\title{
Strip Moment Ratio (SMR) Theory of Plate Analysis for Uniformly Loaded Simply Supported Rectangular Plates with Corners Held Down
}

\author{
Orumu S.T., Ephraim M.E. \\ ${ }^{I}$ Department of Civil Engineering and Hydrology Niger Delta University Wilberforce Island, Nigeria \\ ${ }^{2}$ Department of Civil Engineering Rivers State University of Science and Technology Port Harcourt, Nigeria \\ The research was sponsored by ABSOVI @ COY NIG.
}

\begin{abstract}
An analytical solution of the classical plate bi-harmonic equation for rectangular plates using isolated strip moment ratios SMR is herein presented. It is assumed that the load on the plate is supported by the joint effort of transverse $\mathrm{x}-\mathrm{x}$ strips, longitudinal $\mathrm{y}-\mathrm{y}$ strips and the two diagonal $\mathrm{x}-\mathrm{y}$ strips, acting as isolated simple beams. With the knowledge that the sum of load fractions contributed by the strips equates to unity, the isolated strips are rationed and the load coefficient in each strip is obtained. This reduces the plate problem to a somewhat simple beam problem. The product of the load fraction of a strip and its primitive beam moment and deflection are the required plate moment and deflection respectively. The effect of Poisson ratio and serviceability criterion $\mathrm{h}$ (deflection to span ratio) on plates is also studied. The indication is that an increase in Poisson ratio brings about an increase in the longer span moments of the plate and has got no significant effect on the shorter span moment and deflection of the plate. When the Serviceability criterion is increased and the Poisson ratio kept constant, there is a significant effect on the deflection and moments of the plate. Based on the results of practical application, the SMR method is relatively easier and faster than other methods while the solutions show close agreement with the exact classical results.
\end{abstract}

Keywords: - Plate, strip moment ratio, SMR, load fraction, primitive deflection and moment, Corners held

\section{INTRODUCTION}

The extent and dexterity of application of plates in a vast majority of engineering structure call for ever increasing and deeper research interest into the strength and stiffness characteristics of plate at the ultimate and serviceability limit states of response. Thin plates when subjected to transverse loading suffer bending and undergo transverse deflections which are usually small compared with the thickness of the plate. The governing equation for rectangular plate is familiar and has the form.

$$
\frac{\partial^{4} W}{\partial x^{4} 2}+\frac{2 \partial^{4} w}{\partial x^{2} \partial y^{2}}+\frac{\partial^{4} w}{\partial y^{4}}=\frac{\mathrm{q}}{\mathrm{D}}
$$

Where $\mathrm{q}$ and $\mathrm{D}$ is the load on the plate and the plate stiffness respectively.

, the solution of the above equation has been possible using the infinite trigonometric series and that is only for a limited class of problems. The absence of known trigonometric functions to satisfy some load and displacement functions and boundary conditions is a major drawback of the series solutions. This has prompted the introduction of several approximate methods including the finite element methods $(1,2,3$, and 4$)$. The need to simplify the finite element method and yet obtain good results informed the introduction of the finite strip method [5] and the difference-based finite element method [6]. In the same vein, the grillage analysis (7) and finite difference methods have also been developed, all in an effort to resolve the plate governing equation with relative ease and accuracy. The yield line theory $(8,9,10,11,12)$ and the strip method $(13,14,15,16,17,18)$, which are plastic methods have been developed and applied predominantly for the analysis of reinforced concrete slabs.

This paper is devoted to the development of a modified finite strip theory which the author has christened the strip moment ratio theory. The resulting relationships are simple, fast and easy in application. The proposed strip moment ratio (SMR) method form the major focus of this paper.

\subsection{The basic assumption}

The development of the SMR method is hinged on the following concepts and assumptions.

- The validity of the circular beam theorem.

- The validity of hypothesis of plane section is assumed

- The thickness of plate is considered small compared to its other dimensions. 
- The load q on the plate is supported by the combined effort of the longitudinal $\mathrm{x}$ - strips, the transverse $\mathrm{y}$ strips and the diagonal xy-strips (Figs. 1). Thus, if $\alpha, \beta$ and $\gamma$ are used to denote the contributory load ratio for each type of strips respectively, then the sum of the ratio must be equal to unity. This in effect is a direct interpretation of the governing equation and hence represents an expression of compatibility of deflection at any given point (x,y) of the plate. See figures 2,3,4 and 5 also

The relationships between the load fractions can be expressed in the following equation

$\alpha+\beta+2 \gamma=1$

from which we derive

$\alpha=\frac{1}{1+\frac{g}{\alpha}+\frac{2 P}{\pi}}$

$\beta=\frac{1}{1+\frac{\alpha}{g}+\frac{2 P}{g}}$

$2 \gamma=\frac{1}{1+\frac{a}{2 \gamma}+\frac{g}{2 Y}}$

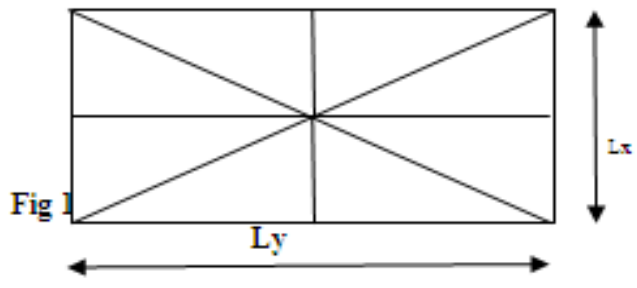

Fig 1

Fig 2

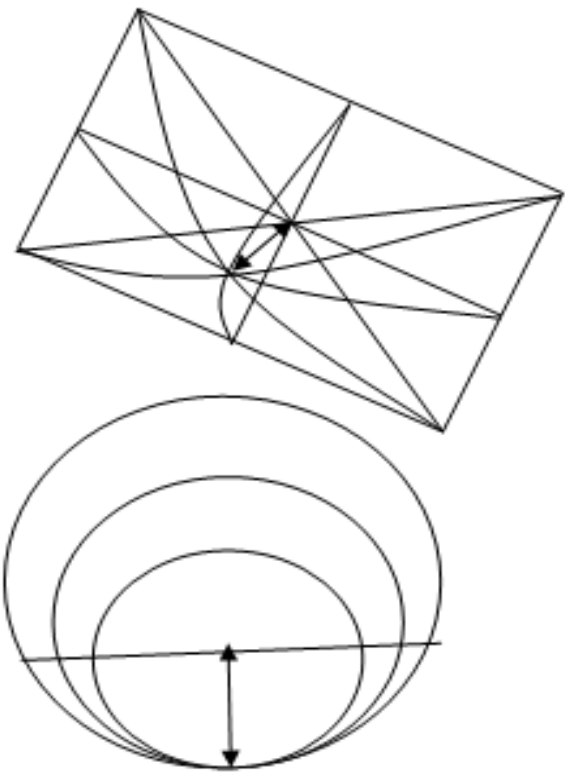

Fig 4

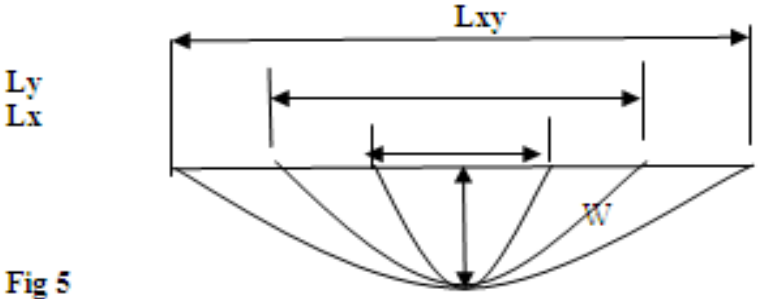

Fig 1 shows the authors' interpretation of the plate bi-harmonic equation as strips in the $\mathrm{x}$-direction, $\mathrm{y}$-direction and xy-directions

Fig 2 shows the deflection form of the plate with the deflection at any point of the plate common to each strip.

Fig 3 shows the circular beam theory. Each of the beam strips bend as a segment of complete circle. The deflection $\mathrm{W}$ shown here is a constant for all the strips.

Fig 4 shows the compatibility of each of the beams of the plate. This introduces the concept of eccentric circles. Here the radii is different for each strip circle but the deflection is always the same

Fig 5 shows an exaggerated section of fig 4. Here actual lengths of each of the beam strips are indicated.

It is further assumed that the plate is undergoing circular bending (Fig. 3 and fig.4) from which the curvatures are derived in the form: 


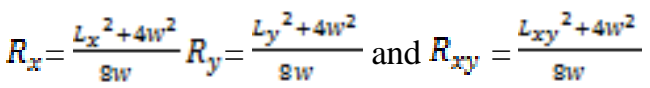

Where $R x, R_{y}, R_{x y}$ are the radii of circle of the $x-x, y-y$ and $x y-x y$ beam strips.

$\mathrm{L}_{\mathrm{x}}, \mathrm{L}_{\mathrm{y}}, \mathrm{L}_{\mathrm{xy}}$ are the length the $\mathrm{x}-\mathrm{x}, \mathrm{y}-\mathrm{y}$ and $\mathrm{xy}-\mathrm{xy}$ beam strips.

$\mathrm{W}$ is the deflection of the plate common to $\mathrm{x}-\mathrm{x}, \mathrm{y}-\mathrm{y}$ and $\mathrm{xy}-\mathrm{xy}$ strips. This is the compartibility condition of the plate model here described.

A limiting value of maximum plate deflection for the small deflection theory of plates is assumed to vary between 0 and 0.005 of the shortest span of plate.

\section{STRIP MOMENT RATIO (SMR)}

The governing equation of thin rectangular plate is given by equation 1. From the equation, the bending and twisting moments per unit length have the following expressions.

$\mathrm{M}_{\mathrm{x}}=\mathrm{D}_{\mathrm{x}} \frac{\partial^{2} W}{\partial x^{2}}+\mathrm{D}_{1} \frac{\partial^{2} W}{\partial y^{2}}=\frac{D_{x}}{R_{x}}+\frac{D_{1}}{R_{y}}$

$\mathrm{M}_{\mathrm{y}}=\mathrm{D}_{1} \frac{\partial^{2} W}{\partial x^{2}}+\mathrm{D}_{\mathrm{y}} \frac{\partial^{2} W}{\partial y^{2}}=\frac{D_{1}}{R_{x}}+\frac{D_{y}}{R_{y}}$

$\mathrm{M}_{\mathrm{xy}}=-2 \mathrm{D}_{\mathrm{xy}} \frac{\partial^{2} w}{\partial x \partial y}=\frac{2 D_{x y}}{R_{x y^{\circ}}}$

Where $\mathrm{Dx}=\frac{E t^{3}}{12\left(1-\mathrm{v}^{2}\right)} \quad \mathrm{D}_{\mathrm{y}}=\frac{\varepsilon t^{3}}{12\left(1-\mathrm{v}^{2}\right)} \quad \mathrm{D}_{\mathrm{xy}}=\frac{G t^{3}}{12}$

$D_{1}=\frac{w E_{x} t^{3}}{12\left(1-w^{2}\right)}$

Where $\mathrm{D}_{2}=\frac{w E_{y} t^{3}}{12\left(1-w^{2}\right)}$

If the primitive beam moments $\mathrm{m}_{\mathrm{x}}$ in the longitudinal $(\mathrm{x}-\mathrm{x}), \mathrm{m}_{\mathrm{y}}$ in the transverse $(\mathrm{y}-\mathrm{y})$ and $\mathrm{m}_{\mathrm{xy}}$ in the two diagonal (xy - xy) strips are factored by load ratios $\alpha, \beta$ and $\gamma$ respectively, then the plate moments become $\mathrm{M}_{\mathrm{x}}=\alpha \mathrm{m}_{\mathrm{x}} ; \mathrm{M}_{\mathrm{y}}=\beta \mathrm{m}_{\mathrm{y}}$ and $\mathrm{M}_{\mathrm{xy}}=2 \gamma \mathrm{m}_{\mathrm{xy}}$

Using the expression for simple beam curvature equations 7,8 and 9 can be represented as follows

$\mathrm{M}_{\mathrm{x}}=\alpha \mathrm{m}_{\mathrm{x}}=\frac{D_{x}}{R_{x}}+\frac{D_{1}}{R_{y}}$

$\mathrm{M}_{\mathrm{y}}=\beta \mathrm{m}_{\mathrm{y}}=\frac{D_{y}}{R_{y}}+\frac{D_{1}}{R_{x}}$

$\mathrm{M}_{\mathrm{xy}}=2 \gamma \mathrm{m}_{\mathrm{xy}}=-2 \mathrm{D}_{\mathrm{xy}} / \mathrm{R}_{\mathrm{xy}}$

Substituting equations 6 into equations 10,11 and 12, the following values of strip moment ratios are determined

$\alpha=\frac{B w}{m_{x}}\left[\frac{D_{x}}{4 w^{2}+L_{x}^{2}}+\frac{D_{1}}{4 w^{2}+L_{y}^{2}}\right)$

$\beta=\frac{\operatorname{sw}}{m_{y}}\left(\frac{D_{y}}{4 w^{2}+L_{y}^{2}}+\frac{D_{1}}{4 w^{2}+L_{x}^{2}}\right)$

$\gamma=\frac{g w}{m_{x y}}\left(\frac{D_{x y}}{4 w^{2}+L_{x y}{ }^{2}}\right)$

Where $L_{x}, L_{y}$ and $L_{x y}$ are the width, length and diagonal dimensions of the plate.

Denoting the aspect ratios $\frac{L_{y}}{L_{x}}=\mathrm{n}$ and $\frac{L_{x y}}{L_{x}}=\mathrm{n}_{\mathrm{z}}$ and the deflection to shortest span ratio $\frac{\mathrm{W}}{L_{x}}=\mathrm{h}$

We have

$\mathrm{L}_{\mathrm{y}}=\mathrm{n} \mathrm{L}_{\mathrm{x}}, \mathrm{L}_{\mathrm{xy}}=\mathrm{L}_{\mathrm{x}} \sqrt{1+n^{2}}=\mathrm{n}_{\mathrm{z}} \mathrm{L}_{\mathrm{x}}$ 
The ratio $\frac{\beta}{\alpha}, \frac{2 p}{\alpha}$ and $\frac{2 p}{\beta}$ can be established thus

$$
\begin{aligned}
& \frac{\beta}{\alpha}=\frac{m_{x}}{m_{y}}\left(\frac{D_{y}}{4 h^{2}+n^{2}}+\frac{D_{1}}{4 h^{2}+1}\right) \div\left(\frac{D_{x}}{4 h^{2}+1}+\frac{D_{1}}{4 h^{2}+n^{2}}\right) \\
& \frac{2 x}{\alpha}=\frac{m_{x}}{m_{x y}}\left(\frac{D_{x y}}{4 h^{2}+n_{x}^{2}}\right) \div\left(\frac{D_{x}}{4 h^{2}+1}+\frac{D_{1}}{4 h^{2}+n^{2}}\right) \quad \text { eqn } 17 \\
& \frac{2 x}{\beta}=\frac{m_{y}}{m_{x y}}\left(\frac{D_{x y}}{4 h^{2}+n_{x}^{2}}\right) \div\left(\frac{D_{1}}{4 h^{2}+1}+\frac{D_{y}}{4 h^{2}+n^{2}}\right) \quad \text { eqn } 18
\end{aligned}
$$

\subsection{Moments}

It is clear that these ratios depend only on the mechanical and geometrical properties of the plate for a given value of h substituting these ratios into equations 3,4 and 5, the strip moment ratios are determined as soon as the primitive strip moments ( $\mathrm{mx}, \mathrm{my}$ and $\mathrm{mxy}$ ) are substituted. These will eventually yield $\alpha, \beta$ and $\gamma$ which are needed for the plate analysis for moments. For Isotropic plate

$\mathrm{D}_{\mathrm{x}}=\mathrm{D}_{\mathrm{y}}=\mathrm{D} ; \mathrm{D}_{1}=\mathrm{D}_{2}=v \mathrm{D}$ and $\mathrm{D}_{\mathrm{xy}}=(1-v) \mathrm{D}$

The plate moments are

$\mathrm{M}_{\mathrm{x}}=\alpha \mathrm{m}_{\mathrm{x}}$

$\mathrm{M}_{\mathrm{y}}=\beta \mathrm{m}_{\mathrm{y}}$ and

$\mathrm{M}_{\mathrm{xy}}=2 \gamma \mathrm{m}_{\mathrm{xy}}$

\section{DEFLECTIONS}

In a similar manner as with the moments, the plate deflections are determined by factoring the primitive beam deflection $\Delta$ of the $\mathrm{x}$ strip by the modified $\mathrm{x}$-x strip moment factor $\propto$. The effect of Poisson ratio $v$ increases the values of $\propto$ and $\beta$ and reduces the value of $\gamma$ see eqn 7,8 and 9 . Therefore the deflection factor $\propto_{\mathrm{x}}$ is obtained where $v$ is made equal to zero in equations 7,8 and 9 . Remember the actual value of $v$ is still intact in the deflection as it is part of the flexural rigidity of the plate.

$\propto{ }_{\mathrm{x}}$ is $\propto$ when $v=0$

The plate deflection $\Delta_{\mathrm{p}}$ is

$\Delta_{\mathrm{p}}=\mathrm{C}_{\mathrm{x}} \Delta$

Where, $\Delta$ is the primitive beam deflection of the $\mathrm{x}$-x strip.

\subsection{Limit of $h=\frac{w}{L_{x}}$}

In order that the derivations are limited to small deflection theory, it is necessary to assess the limit of the deflection. The design codes often specify the value in the form of a ratio, for example $\frac{\mathrm{L}}{\mathrm{a} 60}$ (i.e. $\frac{\mathrm{W}}{\mathrm{L}}=0.0028$ ). The model allows for the input of various values of $h$. The limit of $h$ from the beam theory (see fig 3 ) is between $\mathrm{h}=0$ and $\mathrm{h}=0.5$ when large deflection is expected.

\section{APPLICATION}

For a given plate geometry, all the terms in the equations 16,17 and 18 are known except $\mathrm{h}$. Thus, imputing the allowable $\mathrm{h}$ and the relevant geometric parameters of the plates, the strip moment ratios are determined and hence the plate moments and deflections are obtained. The following solution algorithm is convenient for use in a typical problem.

Step 1: Assume h (allowable $0.5 \leq \mathrm{h} \geq 0$ )

Step 2: Compute plate parameters $n, n_{z}, D_{x}, D_{y}, D_{1}, D_{2}$

Step 3: Compute quantities $\frac{\beta}{\alpha} \times \frac{2 x}{x}$ and $\frac{2 x}{\beta}$ (eqn 16,17and18)

Step 4: Compute $\propto_{x} \beta$ and $2 x$ (eqn 3, 4 and 5).

Step 5: Compute plate moments 
$\mathrm{M}_{\mathrm{x}}=\mathrm{a} \mathrm{m}_{\mathrm{x}}$

$\mathrm{M}_{\mathrm{y}}=\beta \mathrm{m}_{\mathrm{y}}$

$\mathrm{M}_{\mathrm{xy}}=2 \mathrm{\gamma m}_{\mathrm{xy}}$

Step 6: Compute plate deflection (eqn 19 and 20)

\section{PROBLEMS OF INTEREST}

Determine the moments and maximum deflection of a simply supported rectangular Plate with a uniformly distributed load q for various aspect ratios. It is required to find the effect of varying $h$ and Poisson ratio $v$. The solution should be done for the case when corners are held down

6.1 Solution for UDL

The primitive strip moments for this problem are as given below:
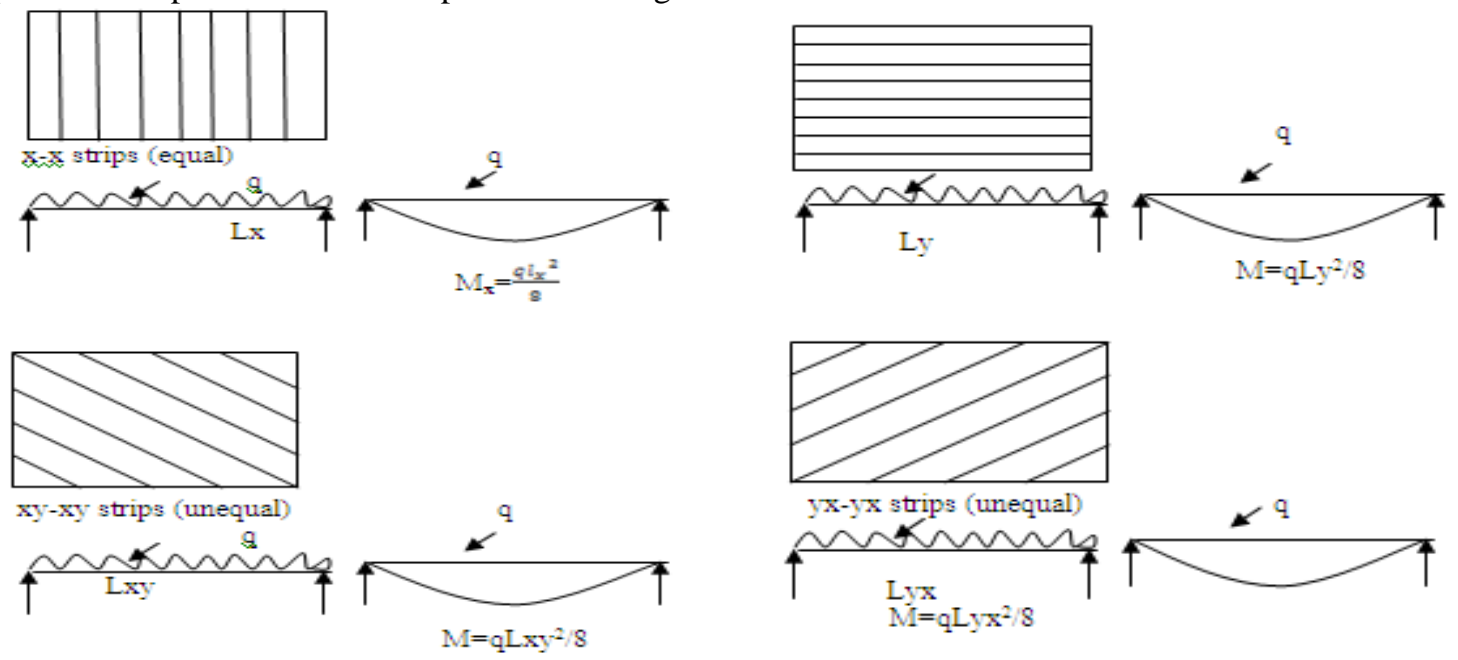

When these moment values are used in the steps listed above, the following results were produced. The average $\mathrm{L}_{\mathrm{xy}}$ or $\mathrm{L}_{\mathrm{yx}}$ is the average length of these unequal strips which is two-third this value.

\subsection{Results}

The results shown below are for various aspect ratio (n) of the plate. $\alpha, \beta$ and $\gamma$ are ratios; $M_{x}$ and $M_{y}$ are coefficients of $\mathrm{qa}^{2}$ and $\Delta$ is coefficient of qa ${ }^{4} / \mathrm{D}$. Where a, is the length of the shorter span and D Is the Plate flexural rigidity.

TABLE 1: load ratio in the $x-x, y-y$ and $x y$ direction together with the bending moments in the $x-x$ and $y-y$ spans of a s-s udl rectangular plate with corners held down. the deflection of the plate is also shown for $\mathrm{h}=0$ and $v=0$. graphical representations are also shown.

\begin{tabular}{|l|l|l|l|l|l|l|}
\hline $\mathrm{n}$ & $\alpha$ & $\beta$ & $\gamma$ & $\mathrm{M}_{\mathrm{x}} \mathrm{sqR} / \mathrm{qa}^{2}$ & $\mathrm{M}_{\mathrm{r} \text { sag }} \mathrm{qa}^{2}$ & $\Delta \mathrm{sNa} / \mathrm{qa}^{4} \mathrm{D}$ \\
\hline 1 & 0.32 & 0.32 & 0.36 & 0.04 & 0.04 & 0.004167 \\
\hline 1.1 & 0.38397 & 0.262257 & 0.353773 & 0.047996 & 0.039666 & 0.005 \\
\hline 1.2 & 0.446808 & 0.215474 & 0.337718 & 0.055851 & 0.038785 & 0.005818 \\
\hline 1.3 & 0.507097 & 0.177549 & 0.315354 & 0.063387 & 0.037507 & 0.006603 \\
\hline 1.4 & 0.563725 & 0.146742 & 0.289532 & 0.070466 & 0.035952 & 0.00734 \\
\hline 1.5 & 0.615928 & 0.121665 & 0.262407 & 0.076991 & 0.034218 & 0.00802 \\
\hline 1.6 & 0.663281 & 0.101209 & 0.23551 & 0.08291 & 0.032387 & 0.008636 \\
\hline 1.7 & 0.705661 & 0.084489 & 0.20985 & 0.088208 & 0.030522 & 0.009188 \\
\hline 1.8 & 0.743179 & 0.070795 & 0.186026 & 0.092897 & 0.028672 & 0.009677 \\
\hline 1.9 & 0.77611 & 0.059554 & 0.164336 & 0.097014 & 0.026874 & 0.010106 \\
\hline 2 & 0.804829 & 0.050302 & 0.144869 & 0.100604 & 0.025151 & 0.01048 \\
\hline 3 & 0.945764 & 0.011676 & 0.042559 & 0.118221 & 0.013136 & 0.012315 \\
\hline 4 & 0.980895 & 0.003832 & 0.015273 & 0.122612 & 0.007663 & 0.012772 \\
\hline 5 & 0.991811 & 0.001587 & 0.006602 & 0.123976 & 0.004959 & 0.012914 \\
\hline 6 & 0.995958 & 0.000768 & 0.003274 & 0.124495 & 0.003458 & 0.012968 \\
\hline 10 & 0.999459 & $9.99 \mathrm{E}-05$ & 0.000441 & 0.124932 & 0.001249 & 0.013014 \\
\hline 100 & 1 & $1 \mathrm{E}-08$ & $4.5 \mathrm{E}-08$ & 0.125 & $1.25 \mathrm{E}-05$ & 0.013021 \\
\hline
\end{tabular}


TABLE 2: load ratio in the $x-x, y-y$ and $x y$ direction together with the bending moments in the $x-x$ and $y-y$ spans of a s-s udl rectangular plate with corners held down. the deflection of the plate is also shown for $h=0$ and $v=0.15$ graphical representations are also shown.

\begin{tabular}{|l|l|l|l|l|l|l|}
\hline $\mathrm{n}$ & $\alpha$ & $\beta$ & $\gamma$ & $\mathrm{M}_{\mathrm{x} \text { SMR }}$ & $\mathrm{M}_{\mathrm{y} \text { SMR }}$ & $\Delta_{\text {SMR }}$ \\
\hline 1 & 0.353167 & 0.353167 & 0.293666 & 0.044146 & 0.044146 & 0.004167 \\
1.1 & 0.414121 & 0.297329 & 0.28855 & 0.051765 & 0.044971 & 0.005 \\
1.2 & 0.473271 & 0.251353 & 0.275376 & 0.059159 & 0.045243 & 0.005818 \\
1.3 & 0.529489 & 0.21344 & 0.257071 & 0.066186 & 0.045089 & 0.006603 \\
1.4 & 0.581929 & 0.182082 & 0.235989 & 0.072741 & 0.04461 & 0.00734 \\
1.5 & 0.630047 & 0.156053 & 0.213899 & 0.078756 & 0.04389 & 0.00802 \\
1.6 & 0.673584 & 0.134375 & 0.192041 & 0.084198 & 0.043 & 0.008636 \\
1.7 & 0.712522 & 0.116258 & 0.17122 & 0.089065 & 0.041998 & 0.009188 \\
1.8 & 0.747025 & 0.101067 & 0.151908 & 0.093378 & 0.040932 & 0.009677 \\
1.9 & 0.777382 & 0.088284 & 0.134333 & 0.097173 & 0.039838 & 0.010106 \\
2 & 0.803952 & 0.077489 & 0.118559 & 0.100494 & 0.038745 & 0.01048 \\
3 & 0.937946 & 0.026766 & 0.035288 & 0.117243 & 0.030112 & 0.012315 \\
4 & 0.974402 & 0.012821 & 0.012777 & 0.1218 & 0.025642 & 0.012772 \\
5 & 0.986992 & 0.007456 & 0.005551 & 0.123374 & 0.023301 & 0.012914 \\
6 & 0.992359 & 0.00488 & 0.002761 & 0.124045 & 0.021961 & 0.012968 \\
10 & 0.998032 & 0.001594 & 0.000374 & 0.124754 & 0.019931 & 0.013014 \\
100 & 0.999985 & $1.5 \mathrm{E}-05$ & $3.82 \mathrm{E}-08$ & 0.124998 & 0.018762 & 0.013021 \\
\hline
\end{tabular}

TABLE 3: load ratio in the $x-x, y-y$ and $x y$ direction together with the bending moments in the $x-x$ and $y-y$ spans of a s-s udl rectangular plate with corners held down. the deflection of the plate is also shown for $h=0$ and $v=0.3$. classical results from timoshenko is also shown. graphical representations are also shown.

\begin{tabular}{|c|c|c|c|c|c|c|c|c|c|}
\hline $\mathrm{n}$ & $a$ & $\beta$ & $\gamma$ & $\mathrm{M}_{\mathrm{s}} \mathrm{gar}$ & $\frac{M_{1}}{\text { Troskenso }}$ & $\mathrm{M}_{\mathrm{S}} \mathrm{Ma}$ & $\begin{array}{l}M_{Y} \\
\text { Thooknewo }\end{array}$ & $\Delta_{\mathrm{SMR}}$ & $\begin{array}{l}\Delta_{\text {TNOOSKEN }} \\
\text { Ho }\end{array}$ \\
\hline 1 & 0.383764 & 0.383764 & 0.232472 & 0.04797 & 0.0479 & 0.04797 & 0.0479 & 0.004167 & 0.00406 \\
\hline 1.1 & 0.441929 & 0.329675 & 0.228395 & 0.055241 & 0.0554 & 0.049863 & 0.0493 & 0.005 & 0.00485 \\
\hline 1.2 & 0.497664 & 0.284425 & 0.217912 & 0.062208 & 0.0627 & 0.051196 & 0.0501 & 0.005818 & 0.00561 \\
\hline 1.3 & 0.550119 & 0.246507 & 0.203374 & 0.068765 & 0.0691 & 0.052075 & 0.0503 & 0.006603 & 0.00638 \\
\hline 1.4 & 0.598696 & 0.214631 & 0.186673 & 0.074837 & 0.0755 & 0.052585 & 0.0502 & 0.00734 & 0.00705 \\
\hline 1.5 & 0.643054 & 0.187733 & 0.169213 & 0.080382 & 0.0812 & 0.0528 & 0.0498 & 0.00802 & 0.00772 \\
\hline 1.6 & 0.683082 & 0.164949 & 0.15197 & 0.085385 & 0.0862 & 0.052784 & 0.0492 & 0.008636 & 0.00830 \\
\hline 1.7 & 0.718853 & 0.145578 & 0.135569 & 0.089857 & 0.0908 & 0.05259 & 0.0486 & 0.009188 & 0.00883 \\
\hline 1.8 & 0.750581 & 0.129049 & 0.12037 & 0.093823 & 0.0948 & 0.052265 & 0.0479 & 0.009677 & 0.00931 \\
\hline 1.9 & 0.778561 & & 0.106545 & 0.09732 & 0.0985 & 0.051846 & 0.0471 & 0.010106 & 0.00974 \\
\hline 2 & 0.803138 & 0.102727 & 0.094135 & 0.100392 & 0.1017 & 0.051363 & 0.0464 & 0.01048 & 0.01013 \\
\hline 3 & 0.930501 & 0.041133 & 0.028365 & 0.116313 & 0.1189 & 0.046275 & 0.0406 & 0.012315 & 0.01223 \\
\hline 4 & 0.968112 & 0.02153 & 0.010358 & 0.121014 & 0.1235 & 0.04306 & 0.0384 & 0.012772 & 0.01282 \\
\hline 5 & 0.982277 & 0.013201 & 0.004523 & 0.122785 & 0.1246 & 0.041252 & 0.0375 & 0.012914 & 0.01297 \\
\hline 6 & 0.988815 & 0.008929 & 0.002256 & 0.123602 & - & 0.040179 & - & 0.012968 & - \\
\hline 10 & 0.996613 & 0.00308 & 0.000307 & 0.124577 & - & 0.038503 & - & 0.013014 & - \\
\hline 100 & 0.99997 & $3 \mathrm{E}-05$ & $3.15 \mathrm{E}-08$ & 0.124996 & 0.125 & 0.03751 & 0.0375 & 0.013021 & 0.01302 \\
\hline
\end{tabular}


TABLE 4: load ratio in the $x-x, y-y$ and $x y$ direction together with the bending moments in the $x-x$ and $y-y$ spans of a s-s udl rectangular plate with corners held down. the deflection of the plate is also shown for $\mathrm{h}=0.25$ and $v=0$. graphical representations are also shown.

\begin{tabular}{|l|l|l|l|l|l|l|}
\hline $\mathrm{n}$ & $\alpha$ & $\beta$ & $\gamma$ & $\mathrm{M}_{\mathrm{x} \text { SMR }}$ & $\mathrm{M}_{\mathrm{y} \text { SMR }}$ & $\Delta_{\text {SMR }}$ \\
\hline 1 & 0.307692 & 0.307692 & 0.384615 & 0.038462 & 0.038462 & 0.004006 \\
1.1 & 0.364667 & 0.258029 & 0.377304 & 0.045583 & 0.039027 & 0.004748 \\
1.2 & 0.421827 & 0.216668 & 0.361505 & 0.052728 & 0.039 & 0.005493 \\
1.3 & 0.477895 & 0.182202 & 0.339903 & 0.059737 & 0.03849 & 0.006223 \\
1.4 & 0.53175 & 0.153451 & 0.314799 & 0.066469 & 0.037595 & 0.006924 \\
1.5 & 0.582504 & 0.129445 & 0.288051 & 0.072813 & 0.036406 & 0.007585 \\
1.6 & 0.629533 & 0.109391 & 0.261076 & 0.078692 & 0.035005 & 0.008197 \\
1.7 & 0.672483 & 0.092633 & 0.234884 & 0.08406 & 0.033464 & 0.008756 \\
1.8 & 0.711231 & 0.078623 & 0.210146 & 0.088904 & 0.031842 & 0.009261 \\
1.9 & 0.74584 & 0.066905 & 0.187254 & 0.09323 & 0.030191 & 0.009711 \\
2 & 0.776509 & 0.057096 & 0.166395 & 0.097064 & 0.028548 & 0.010111 \\
3 & 0.934673 & 0.014034 & 0.051293 & 0.116834 & 0.015788 & 0.01217 \\
4 & 0.976573 & 0.004695 & 0.018732 & 0.122072 & 0.00939 & 0.012716 \\
5 & 0.989881 & 0.00196 & 0.008158 & 0.123735 & 0.006126 & 0.012889 \\
6 & 0.994986 & 0.000953 & 0.004061 & 0.124373 & 0.004289 & 0.012956 \\
10 & 0.999326 & 0.000125 & 0.00055 & 0.124916 & 0.001558 & 0.013012 \\
100 & 1 & $1.25 \mathrm{E}-08$ & $5.62 \mathrm{E}-08$ & 0.125 & $1.56 \mathrm{E}-05$ & 0.013021 \\
\hline
\end{tabular}

TABLE 5: load ratio in the $x-x, y-y$ and $x y$ direction together with the bending moments in the $x-x$ and $y-y$ spans of a s-s udl rectangular plate with corners held down. the deflection of the plate is also shown for $\mathrm{h}=0.25$ and $v=0.15$. graphical representations are also shown.

\begin{tabular}{|l|l|l|l|l|l|l|}
\hline $\mathrm{n}$ & $\alpha$ & $\beta$ & $\gamma$ & $\mathrm{M}_{\mathrm{x} \text { SMR }}$ & $\mathrm{M}_{\mathrm{y} \text { SMR }}$ & $\Delta_{\text {SMR }}$ \\
\hline 1 & 0.342007 & 0.342007 & 0.315985 & 0.042751 & 0.042751 & 0.004006 \\
1.1 & 0.397414 & 0.292856 & 0.309731 & 0.049677 & 0.044294 & 0.004748 \\
1.2 & 0.452118 & 0.251428 & 0.296454 & 0.056515 & 0.045257 & 0.005493 \\
1.3 & 0.505082 & 0.216475 & 0.278443 & 0.063135 & 0.04573 & 0.006223 \\
1.4 & 0.555431 & 0.186932 & 0.257637 & 0.069429 & 0.045798 & 0.006924 \\
1.5 & 0.602505 & 0.161913 & 0.235582 & 0.075313 & 0.045538 & 0.007585 \\
1.6 & 0.645878 & 0.140688 & 0.213434 & 0.080735 & 0.04502 & 0.008197 \\
1.7 & 0.685344 & 0.122652 & 0.192005 & 0.085668 & 0.044308 & 0.008756 \\
1.8 & 0.720883 & 0.1073 & 0.171817 & 0.09011 & 0.043456 & 0.009261 \\
1.9 & 0.752618 & 0.094209 & 0.153172 & 0.094077 & 0.042512 & 0.009711 \\
2 & 0.780771 & 0.083026 & 0.136203 & 0.097596 & 0.041513 & 0.010111 \\
3 & 0.928702 & 0.028838 & 0.04246 & 0.116088 & 0.032443 & 0.01217 \\
4 & 0.970743 & 0.013611 & 0.015647 & 0.121343 & 0.027221 & 0.012716 \\
5 & 0.985343 & 0.007805 & 0.006852 & 0.123168 & 0.024391 & 0.012889 \\
6 & 0.991523 & 0.005055 & 0.003422 & 0.12394 & 0.022747 & 0.012956 \\
10 & 0.997916 & 0.001618 & 0.000466 & 0.12474 & 0.020228 & 0.013012 \\
100 & 0.999985 & $1.5 \mathrm{E}-05$ & $4.78 \mathrm{E}-08$ & 0.124998 & 0.018765 & 0.013021 \\
\hline
\end{tabular}

TABLE 6: load ratio in the $x-x, y-y$ and $x y$ direction together with the bending moments in the $x-x$ and $y-y$ spans of a s-s udl rectangular plate with corners held down. the deflection of the plate is also shown for $\mathrm{h}=0.25$ and $v=0.3$. classical results from Timoshenko is also shown. Graphical representations are also shown. 


\begin{tabular}{|c|c|c|c|c|c|c|c|c|c|}
\hline $\mathrm{n}$ & $a$ & $\beta$ & $y$ & $M_{x} \Omega R$ & \begin{tabular}{|l|}
$\mathrm{M}_{\mathrm{x}}$ \\
TMONHENO \\
\end{tabular} & $\mathrm{M}_{\mathrm{HSR}}$ & $\begin{array}{l}\mathrm{MY}_{\mathrm{Y}} \\
\text { TMOSHENO }\end{array}$ & $\Delta \mathrm{SaR}$ & $\Delta_{\text {TnNoshew }}$ \\
\hline 1 & 0.374101 & 0.374101 & 0.251799 & 0.046763 & 0.0479 & 0.046763 & 0.0479 & 0.004006 & 0.00406 \\
\hline 1.1 & 0.427993 & 0.325377 & 0.24663 & 0.053499 & 0.0554 & 0.049213 & 0.0493 & 0.004748 & 0.00485 \\
\hline 1.2 & 0.480348 & 0.283821 & 0.235831 & 0.060043 & 0.0627 & 0.051088 & 0.0501 & 0.005493 & 0.00561 \\
\hline 1.3 & 0.530367 & 0.24835 & 0.221283 & 0.066296 & 0.0691 & 0.052464 & 0.0503 & 0.006223 & 0.00638 \\
\hline 1.4 & 0.577415 & 0.218015 & 0.204571 & 0.072177 & 0.0755 & 0.053414 & 0.0502 & 0.006924 & 0.00705 \\
\hline 1.5 & 0.621048 & 0.192015 & 0.186937 & 0.077631 & 0.0812 & 0.054004 & 0.0498 & 0.007585 & 0.00772 \\
\hline 16 & 0.661019 & 0.169681 & 0.1693 & 0.082627 & 0.0862 & 0.054298 & 0.0492 & 0.008197 & 0.00830 \\
\hline 1.7 & 0.697256 & 0.150456 & 0.152288 & 0.087157 & 0.0908 & 0.054352 & 0.0486 & 0.008756 & 0.00883 \\
\hline 1.8 & 0.729827 & 0.133871 & 0.136303 & 0.091228 & 0.0948 & 0.054218 & 0.0479 & 0.009261 & 0.00931 \\
\hline 1.9 & 0.758904 & 0.119532 & 0.121564 & 0.094863 & 0.0985 & 0.053939 & 0.0471 & 0.009711 & 0.00974 \\
\hline 2 & 0.78473 & 0.107105 & 0.108165 & 0.098091 & 0.1017 & 0.053552 & 0.0464 & 0.010111 & 0.01013 \\
\hline 3 & 0.923035 & 0.042888 & 0.034077 & 0.115379 & 0.1189 & 0.04825 & 0.0406 & 0.01217 & 0.01223 \\
\hline 4 & 0.965111 & 0.022223 & 0.012666 & 0.120639 & 0.1235 & 0.044446 & 0.0384 & 0.012716 & 0.01282 \\
\hline 5 & 0.980911 & 0.013513 & 0.005576 & 0.122614 & 0.1246 & 0.042227 & 0.0375 & 0.012889 & 0.01297 \\
\hline 6 & 0.988119 & 0.009087 & 0.002794 & 0.123515 & - & 0.040891 & $\therefore$ & 0.012956 & $\therefore$ \\
\hline 10 & 0.996516 & 0.003102 & 0.000382 & 0.124564 & - & 0.038777 & - & 0.013012 & - \\
\hline 100 & 0.99997 & $3 \mathrm{E}-05$ & $3.94 \mathrm{E}-08$ & 0.124996 & 0.125 & 0.037513 & 0.0375 & 0.013021 & 0.01302 \\
\hline
\end{tabular}

TABLE 7: load ratio in the $x-x, y-y$ and $x y$ direction together with the bending moments in the $x-x$ and $y-y$ spans of a s-s udl rectangular plate with corners held down. The deflection of the plate is also shown for $h=0.5$ and $\mathrm{v}=0$. graphical representations are also shown.

\begin{tabular}{|l|l|l|l|l|l|l|}
\hline $\mathrm{n}$ & $\alpha$ & $\beta$ & $\gamma$ & $\mathrm{M}_{\mathrm{x} \text { SMR }}$ & $\mathrm{M}_{\mathrm{y} \text { SMR }}$ & $\Delta_{\mathrm{SMR}}$ \\
\hline 1 & 0.285714 & 0.285714 & 0.428571 & 0.035714 & 0.035714 & 0.00372 \\
1.1 & 0.331502 & 0.247935 & 0.420563 & 0.041438 & 0.0375 & 0.004316 \\
1.2 & 0.378578 & 0.215493 & 0.405929 & 0.047322 & 0.038789 & 0.004929 \\
1.3 & 0.426142 & 0.187476 & 0.386383 & 0.053268 & 0.039604 & 0.005549 \\
1.4 & 0.473363 & 0.163183 & 0.363454 & 0.05917 & 0.03998 & 0.006164 \\
1.5 & 0.519457 & 0.142074 & 0.33847 & 0.064932 & 0.039958 & 0.006764 \\
1.6 & 0.563743 & 0.123715 & 0.312542 & 0.070468 & 0.039589 & 0.00734 \\
1.7 & 0.60568 & 0.107752 & 0.286568 & 0.07571 & 0.038925 & 0.007886 \\
1.8 & 0.644882 & 0.093886 & 0.261232 & 0.08061 & 0.038024 & 0.008397 \\
1.9 & 0.681117 & 0.081855 & 0.237028 & 0.08514 & 0.036937 & 0.008869 \\
2 & 0.714286 & 0.071429 & 0.214286 & 0.089286 & 0.035714 & 0.009301 \\
3 & 0.905764 & 0.020128 & 0.074108 & 0.11322 & 0.022644 & 0.011794 \\
4 & 0.964539 & 0.007092 & 0.028369 & 0.120567 & 0.014184 & 0.012559 \\
5 & 0.984351 & 0.003029 & 0.01262 & 0.123044 & 0.009465 & 0.012817 \\
6 & 0.992159 & 0.00149 & 0.006351 & 0.12402 & 0.006704 & 0.012919 \\
10 & 0.99893 & 0.000198 & 0.000873 & 0.124866 & 0.002473 & 0.013007 \\
100 & 1 & $2 \mathrm{E}-08$ & $9 \mathrm{E}-08$ & 0.125 & $2.5 \mathrm{E}-05$ & 0.013021 \\
\hline
\end{tabular}


TABLE 8: load ratio in the $x-x, y-y$ and $x y$ direction together with the bending moments in the $x-x$ and $y-y$ spans of a s-s udl rectangular plate with corners held down. The deflection of the plate is also shown for $\mathrm{h}=0.5$ and $\mathbb{v}=0.15$. graphical representations are also shown.

\begin{tabular}{|l|l|l|l|l|l|l|}
\hline $\mathrm{n}$ & $\alpha$ & $\beta$ & $\gamma$ & $\mathrm{M}_{\mathrm{x} \text { SMR }}$ & $\mathrm{M}_{\mathrm{y} \text { SMR }}$ & $\Delta_{\text {SMR }}$ \\
\hline 1 & 0.321678 & 0.321678 & 0.356643 & 0.04021 & 0.04021 & 0.00372 \\
1.1 & 0.368033 & 0.282529 & 0.349438 & 0.046004 & 0.042733 & 0.004316 \\
1.2 & 0.414718 & 0.248688 & 0.336594 & 0.05184 & 0.044764 & 0.004929 \\
1.3 & 0.461038 & 0.219292 & 0.319669 & 0.05763 & 0.046325 & 0.005549 \\
1.4 & 0.506309 & 0.193661 & 0.30003 & 0.063289 & 0.047447 & 0.006164 \\
1.5 & 0.549914 & 0.171256 & 0.27883 & 0.068739 & 0.048166 & 0.006764 \\
1.6 & 0.591347 & 0.151643 & 0.257011 & 0.073918 & 0.048526 & 0.00734 \\
1.7 & 0.63023 & 0.134461 & 0.235309 & 0.078779 & 0.048574 & 0.007886 \\
1.8 & 0.666324 & 0.119407 & 0.214269 & 0.08329 & 0.04836 & 0.008397 \\
1.9 & 0.699509 & 0.106218 & 0.194272 & 0.087439 & 0.047931 & 0.008869 \\
2 & 0.729776 & 0.094664 & 0.175559 & 0.091222 & 0.047332 & 0.009301 \\
3 & 0.904751 & 0.03416 & 0.061089 & 0.113094 & 0.03843 & 0.011794 \\
4 & 0.960611 & 0.01579 & 0.023599 & 0.120076 & 0.031581 & 0.012559 \\
5 & 0.980636 & 0.0088 & 0.010565 & 0.122579 & 0.027499 & 0.012817 \\
6 & 0.9891 & 0.005561 & 0.005338 & 0.123638 & 0.025026 & 0.012919 \\
10 & 0.997573 & 0.001689 & 0.000739 & 0.124697 & 0.021111 & 0.013007 \\
100 & 0.999985 & $1.5 \mathrm{E}-05$ & $7.65 \mathrm{E}-08$ & 0.124998 & 0.018774 & 0.013021 \\
\hline
\end{tabular}

TABLE 9: load ratio in the $x-x, y-y$ and $x y$ direction together with the bending moments in the $x-x$ and $y-y$ spans of a s-s udl rectangular plate with corners held down. the deflection of the plate is also shown for $\mathrm{h}=0.5$ and $v=0.3$. classical results from Timoshenko is also shown. graphical representations are also shown.

\begin{tabular}{|c|c|c|c|c|c|c|c|c|c|}
\hline $\mathrm{n}$ & $\alpha$ & $\beta$ & $y$ & $\mathrm{M}_{\mathrm{x} \mathrm{SM}}$ & \begin{tabular}{|l}
$\mathrm{M}_{\mathrm{x}}$ \\
$\mathrm{TWNOSHE}$ \\
$\mathrm{NRO}$ \\
\end{tabular} & $\mathrm{M}_{\mathrm{rag}}$ & $\begin{array}{l}\mathrm{M}_{\mathrm{Y}} \\
\text { TnOOSHE } \\
\text { NRO }\end{array}$ & $\Delta \mathrm{SaR}$ & $\begin{array}{l}\Delta_{\text {TnMOSHEN }} \\
\mathrm{BO}\end{array}$ \\
\hline 1 & 0.356164 & 0.356164 & 0.287671 & 0.044521 & 0.0479 & 0.044521 & 0.0479 & 0.00372 & 0.00406 \\
\hline 1.1 & 0.402957 & 0.315601 & 0.281442 & 0.05037 & 0.0554 & 0.047735 & 0.0493 & 0.004316 & 0.00485 \\
\hline 1.2 & 0.449132 & 0.280297 & 0.270572 & 0.056141 & 0.0627 & 0.050453 & 0.0501 & 0.004929 & 0.00561 \\
\hline 1.3 & 0.494123 & 0.249456 & 0.256421 & 0.061765 & 0.0691 & 0.052698 & 0.0503 & 0.005549 & 0.00638 \\
\hline 1.4 & 0.537409 & 0.222431 & 0.24016 & 0.067176 & 0.0755 & 0.054496 & 0.0502 & 0.006164 & 0.00705 \\
\hline 1.5 & 0.578549 & 0.198694 & 0.222757 & 0.072319 & 0.0812 & 0.055883 & 0.0498 & 0.006764 & 0.00772 \\
\hline 1.6 & 0.617209 & 0.177809 & 0.204982 & 0.077151 & 0.0862 & 0.056899 & 0.0492 & 0.00734 & 0.00830 \\
\hline 1.7 & 0.653168 & 0.159415 & 0.187417 & 0.081646 & 0.0908 & 0.057589 & 0.0486 & 0.007886 & 0.00883 \\
\hline 1.8 & 0.686314 & 0.143201 & 0.170485 & 0.085789 & 0.0948 & 0.057996 & 0.0479 & 0.008397 & 0.00931 \\
\hline 1.9 & 0.716633 & 0.1289 & 0.154467 & 0.089579 & 0.0985 & 0.058166 & 0.0471 & 0.008869 & 0.00974 \\
\hline 2 & 0.744186 & 0.116279 & 0.139535 & 0.093023 & 0.1017 & 0.05814 & 0.0464 & 0.009301 & 0.01013 \\
\hline 3 & 0.903798 & 0.047369 & 0.048833 & 0.112975 & 0.1189 & 0.05329 & 0.0406 & 0.011794 & 0.01223 \\
\hline 4 & 0.956847 & 0.024125 & 0.019028 & 0.119606 & 0.1235 & 0.04825 & 0.0384 & 0.012559 & 0.01282 \\
\hline 5 & 0.977031 & 0.014398 & 0.00857 & 0.122129 & 0.1246 & 0.044995 & 0.0375 & 0.012817 & 0.01297 \\
\hline 6 & 0.986109 & 0.009543 & 0.004348 & 0.123264 & - & 0.042946 & - & 0.012919 & $\therefore$ \\
\hline 10 & 0.996227 & 0.003167 & 0.000606 & 0.124528 & - & 0.039589 & - & 0.013007 & - \\
\hline 100 & 0.99997 & $3 \mathrm{E}-05$ & $6.3 \mathrm{E}-08$ & 0.124996 & 0.125 & 0.037522 & 0.0375 & 0.013021 & 0.01302 \\
\hline
\end{tabular}


TABLE 10: load ratio in the $x-x, y-y$ and $x y$ direction together with the bending moments in the $x-x$ and $y-y$ spans of a s-s udl rectangular plate with corners held down. the deflection of the plate is also shown for $\mathrm{h}=0.15$ and $\mathrm{v}=0.3$. classical results from Timoshenko is also shown. Graphical representations are also shown.

\begin{tabular}{|c|c|c|c|c|c|c|c|c|c|}
\hline $\mathrm{n}$ & $a$ & $\beta$ & $\gamma$ & $M_{x} \operatorname{sar}$ & $\begin{array}{l}\mathrm{M}_{\mathrm{x}} \\
\text { TMOOSHENOO }\end{array}$ & $\mathrm{M}_{\mathrm{rSSR}}$ & $\begin{array}{l}\mathrm{M}_{\mathrm{Y}} \\
\text { TINOSHENWO }\end{array}$ & $\Delta_{\mathrm{SMR}}$ & $\begin{array}{l}\Delta_{\text {TMNOSHENK }} \\
0\end{array}$ \\
\hline 1 & 0.37996 & 0.37996 & 0.24008 & 0.047495 & 0.0479 & 0.047495 & 0.0479 & 0.004103 & 0.00406 \\
\hline 1.1 & 0.436395 & 0.328072 & 0.235533 & 054549 & 0.0554 & 0.049621 & 0.0493 & 0.004899 & 0.00485 \\
\hline 1.2 & 0.490793 & 284299 & 0.22 & 61349 & 0.0627 & 0.051174 & 0.0501 & 0.005688 & 0.00 \\
\hline 1.3 & 0.54 & 0.24 & 0.2 & 789 & 0.0691 & 249 & 0.0503 & 452 & 0.00 \\
\hline 1.4 & 0.5 & 1 & & & 0.0755 & & 0.0502 & & 0.00 \\
\hline 1.5 & 0.6 & 0.189467 & 0.1 & 07 & 0.0812 & & 0.0498 & 449 & 0.00 \\
\hline 1.6 & 0.674513 & 0.16 & 0.1 & 4314 & 0.0862 & 387 & 0.0492 & 465 & 0.00830 \\
\hline 1.7 & 0.7 & 0.14 & 0.1 & 814 & 0.0908 & 283 & 0.0486 & 021 & 0.00 \\
\hline 1.8 & 0.74 & 0.13 & 0.1 & 326 & 0.0948 & 25 & 0.0479 & 0.0 & 0.00931 \\
\hline 1.9 & 0.7 & 0.116 & 0.1 & 81 & 0.0985 & 0.0 & 0.0471 & 0.0 & 0.00974 \\
\hline 2 & 0.796137 & 0.104406 & 0.099456 & 0.099517 & 0.1017 & 0.052203 & 0.0464 & 0.010339 & 0.01013 \\
\hline 3 & 0.927744 & 0.041783 & 0.030474 & 0.115968 & 0.1189 & 0.047005 & 0.0406 & 0.012261 & 0.01223 \\
\hline 4 & 0.967016 & 0.021783 & 0.011201 & 0.120877 & 0.1235 & 0.043566 & 0.0384 & 0.012752 & 0.01282 \\
\hline 5 & 0.981781 & 0.013314 & 0.004905 & 0.122723 & 0.1246 & 0.041606 & 0.0375 & 0.012905 & 0.01297 \\
\hline 6 & 0.988563 & 0.008986 & 0.002451 & 0.12357 & 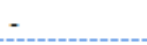 & 0.040437 & - & 0.012964 & $\therefore$ \\
\hline 10 & 0.996578 & 0.003088 & 0.000334 & 0.124572 & $\therefore$ & 0.038602 & $\therefore$ & 0.013013 & $\therefore$ \\
\hline 100 & 0.99997 & $3 \mathrm{E}-05$ & $3.43 \mathrm{E}-08$ & 0.124996 & 0.125 & 0.037511 & 0.0375 & 0.013021 & 0.01302 \\
\hline
\end{tabular}

\subsection{Discussion of Results:}

The results obtained from the application of the SMR theory to S-S plate problems show great promises in the analysis of problems in continuums. Tables 1 to 10 show the effect of $\mathrm{h}$ and poison ratio $\mathrm{v}$ on the moments and deflection of S-S rectangular Plates when corners are held down. Tables 3, 6, 9 and 10 make comparison with the classical methods as reported by Timoshenko for the plate under investigation. It is of particular interest to note that when $\mathrm{h}$ tends to zero the classical results are obtained for moments in the shorter span and the deflection. The classical moments in the shorter span and deflection tend to converge a little more rapid than those obtained using the SMR method. On the other hand the longer span moment using SMR method converges a little more rapid than those obtained using the classical method. The effect of Poisson ratio on the results can be easily observed in charts 1,2 and 3. Here it is clear that Poisson ratio affects the longer span moment greatly. As the aspect ratio increases the moments for various aspect ratios diverge. While for $\mathrm{v}=0$ it tends to zero, for $\mathrm{v}=0.3$ it tends to $0.0375 \mathrm{qa}^{2}$. The effect of Poisson ratio (v) on the shorter span moment and deflection is almost insignificant. As the aspect ratio of the plate increases the results asymptotes to $0.125 \mathrm{qa}^{2}$ for moment and $0.013021 \mathrm{qa}^{4} / \mathrm{D}$ for deflection. This is for any value of Poisson ratio v. the effect of the serviceability criterion $\mathrm{h}$ on moments and deflection is significant. Charts 4, 5 and 6 show that for a given Poisson ratio, the shorter span moment and the deflection of the plate produce results which are arranged in such a way that the outermost chart has the least value of $h(0)$ while the innermost chart has the greatest $h(0.5)$. These graphs however meet in plates of large aspect ratio. The value of $h$ affects the longer span moment in such a way that the largest $\mathrm{h}(0.5)$ begins with the least moments and climbs up until an aspect ratio of 1.5 having the largest moment and dropping in value, yet maintaining the lead till the point when they converge in plates of very large aspect ratio. The reverse is the case with the least $\mathrm{h}(0)$ which begins with the largest results of moment and just within an aspect ratio of 1.2 drops to have the least result until they meet at point infinite.

\section{CONCLUSION.}

A new method for the analysis of plate has been developed. It concentrates on the isolated beam strips that make up the plate equation. Prerequisites for the integration of a third load carrying layer $x y-x y$ to the presently used two layers of a plate is worked out, with a view to achieving a more accurate representation of the bi-harmonic plate equation. The simple beam theory is used to get strip moment ratios which has a serviceability criterion $\mathrm{h}$ (deflection/span). With the assumption that the sum of loads of the strips is unity, the isolated strips are rationed, and the load fraction in every strip is known, thus the plate problem is reduced to a simple beam problem. Several exact results were confirmed and without any modification can be used in the design office. The practical significance of the research consists in the fact that the established SMR method for the analysis of uniformly loaded simply supported rectangular plates:- 
- Enhances close agreement of the theoretical prediction with code value, which is the combination of experimental values and elastic method predictions.

- Permits quantitative estimation of moments and deflections of plates in a simple way. Plates of any material can be analyzed and designed because Poisson ratio is adequately taken care of.

- Permits the use of serviceability limit of deflection which primitive value or expected value can be inputted into the model before the solution is obtained.

- May be incorporated in scientific research codes of practice the areas of steel, plastic, wood, re-inforced concrete and any other material.

The SMR method has been extended to plates of various support conditions and load types. It has also been extended to Skew plates, irregular plates, circular plates, Triangular plates with great accuracy. Plate vibration and plate buckling problems have also been solved with the method. The work has been broken down into several papers because of space.

\section{ACKNOWLEDGEMENT}

To make this work a success, the efforts of Professor T. Johnarry and Professor J.G. Chinwah are dearly appreciated. I am greatly indebted to ABSOVI \& COY Nigeria (Civil Engineering Consultants) who funded the research.

\section{REFERENCES}

[1] Zienkiewiez, O.C. Finite Element Method in Engineering Science. Second edition McGraw-Hill Publication Co. Ltd. London. (1971) Pp. 398

[2] Rocky, K.C. The Finite Element, Granada Publication Ltd. London. (1975) 45-80

[3] Iron, B. Techniques of Finite Element Ellis Horwood Ltd, England(1980) 1-100

[4] E. Hinton, O.C. zeinkiewicz, \& J.D. Davies : A Simple Finite Element Solution for Plates of Homogeneous, Sandwich and Cellular Construction; Proc. Instn. Civil Engineers. Part 2 (1975), 43-65

[5] A.R. Cusens\& Y.C. Loo. Application of the Finite Strip Method in the Analysis of Concrete Box Bridges; Proc. Instn. Civil Engineers part 259 (1975) 189-192

[6] C.T. Morley Equilibrium Design Solutions for Torsionless Grillages or Hillerborg Slabs under Concentrated Loads; Proc. Instn. Civil Engineers, part 2 (1986) 81, 447-460

[7] Jone, L.L. \& Wood, R.H. Yield-Line Analysis of Slabs. Thames and Hudson, Chatto and Windus, London. (1967) Pp. 200

[8] Johansen, K.W. Yield-Line Theory (English Translation) Cement and Concrete Association, London (1962). 144-150

[9] Johnarry, T. Support Reaction and its Implication for Orthotropy in the Yield-Line Method Magazine of Concrete Research, 44. No. 161 (1992) 249-254

[10] Satish, C. Jain \& John, B. Kennedy, Yield Criterion for Reinforced Concrete Slabs, Ibid Vol. 100, No. ST3 (1974) 876-880

[11] VijayaRangan, B. Limit States Design of Slabs using Lower Bound Approach. Ibid Vol. 100, No. ST2 (1974) 665-671

[12] Hillerborg, A. Strip Method of Slab Design. View Point Publications, Cement and Concrete Association; London. (1974) 190-200

[13] Kemp, K.O. A Strip Method of Slab Design with Concentrated Loads or Supports. The Structural Engineer, Vol. 49, No. 12(1971)

[14] Hillerborg A. Strip Method of Design. London View Point (1975) pp. 225

[15] Fenado, J.S. \& Kemp, K.O. A Generalized Strip Deflection Method of Reinforced Concrete Slab Design. Proceeding of the Institution of Civil Engineers, part 2, Research and Theory 65(1978) 37-44

[16] Arne Hillerbog: The Advanced Strip Method - A simple Design Tool: Magazine of Concrete Research: Vol. 34, No.121: (1982) 706-718

[17] BS 8110 British Standard Institute (1998)

[18] Timoshenko \& Woinowsky - Krieger Theory of Plates and Shells, McGraw-Hill Kogakusha, Ltd. 2nd ed. Pp.400

[19] Orumu, S.T- Serviceability Solution Of Rectangular Plates From Isolated Strip Moments Ratio (SMR). Doctoral Dissertation Submitted To Rivers State University Of Science And Technology Port Harcourt. (2002). 

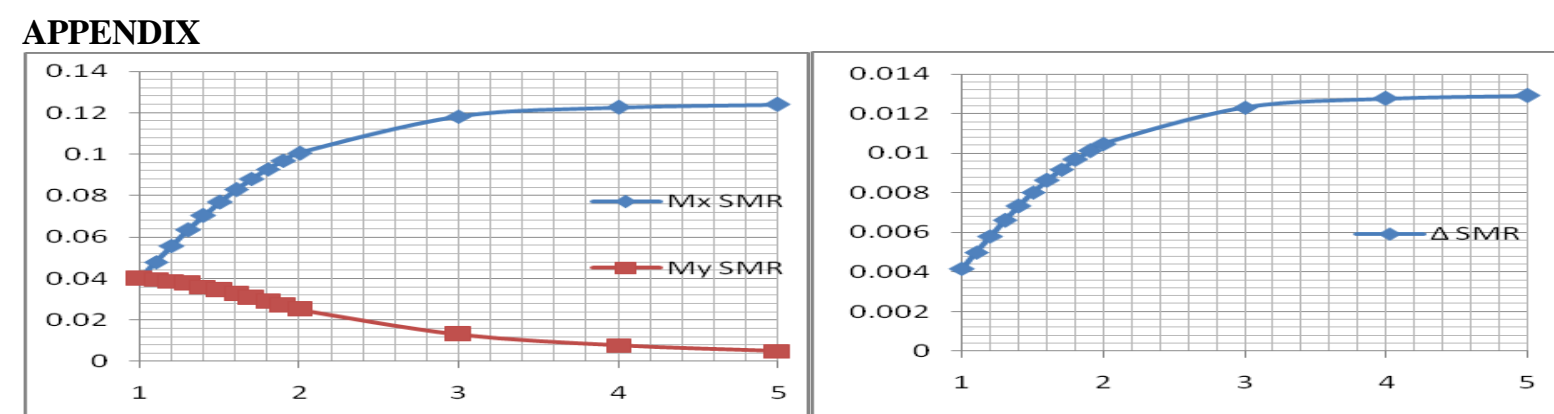

chart 1: load ratio in the $\mathrm{x}-\mathrm{x}, \mathrm{y}-\mathrm{y}$ and $\mathrm{xy}$ direction together with the bending moments in the $\mathrm{x}-\mathrm{x}$ and $\mathrm{y}-\mathrm{y}$ spans of a s-s udl rectangular plate with corners held down. the deflection of the plate is also shown for $\mathrm{h}=0$ and $V=0$. graphical representations are also shown.
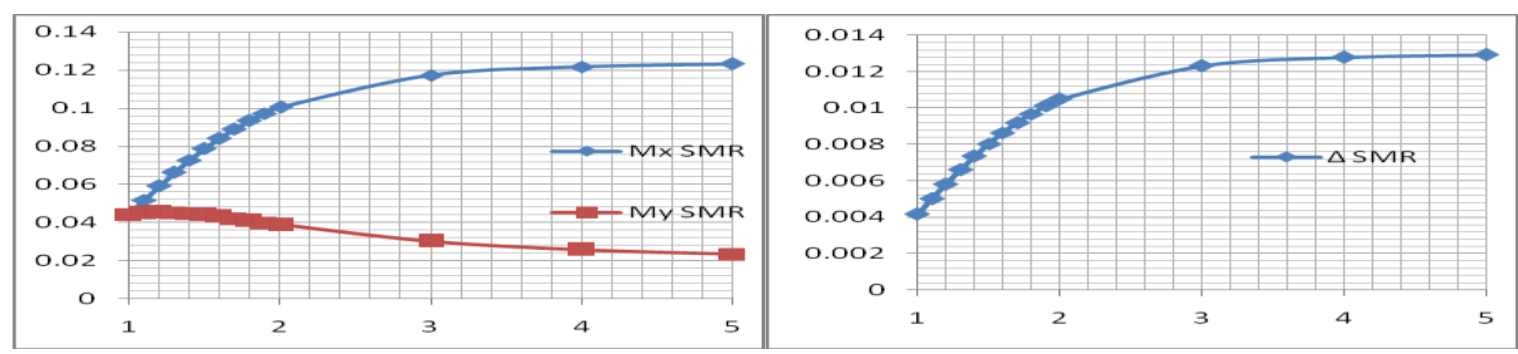

chart 2: load ratio in the $\mathrm{x}-\mathrm{x}, \mathrm{y}-\mathrm{y}$ and $\mathrm{xy}$ direction together with the bending moments in the $\mathrm{x}-\mathrm{x}$ and $\mathrm{y}-\mathrm{y}$ spans of a s-s udl rectangular plate with corners held down. the deflection of the plate is also shown for $\mathrm{h}=0$ and $v$ $=0.15$ graphical representations are also shown.
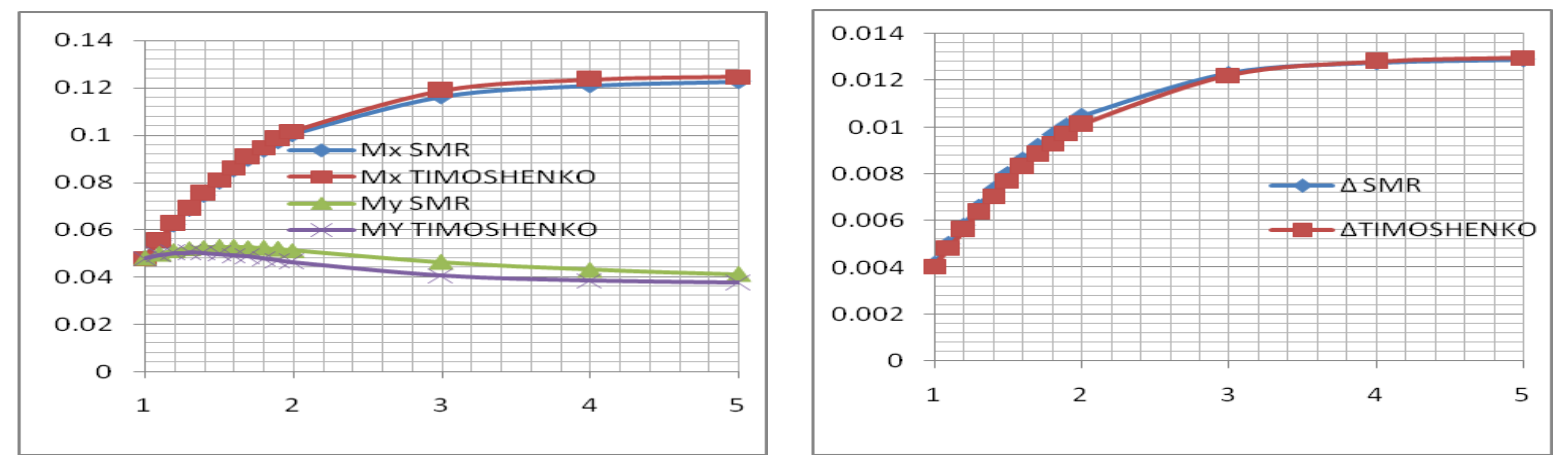

chart 3: load ratio in the $\mathrm{x}-\mathrm{x}, \mathrm{y}-\mathrm{y}$ and $\mathrm{xy}$ direction together with the bending moments in the $\mathrm{x}-\mathrm{x}$ and $\mathrm{y}-\mathrm{y}$ spans of a s-s udl rectangular plate with corners held down. the deflection of the plate is also shown for $\mathrm{h}=0$ and $v$ $=0.3$. classical results from timoshenko is also shown. graphical representations are also shown.
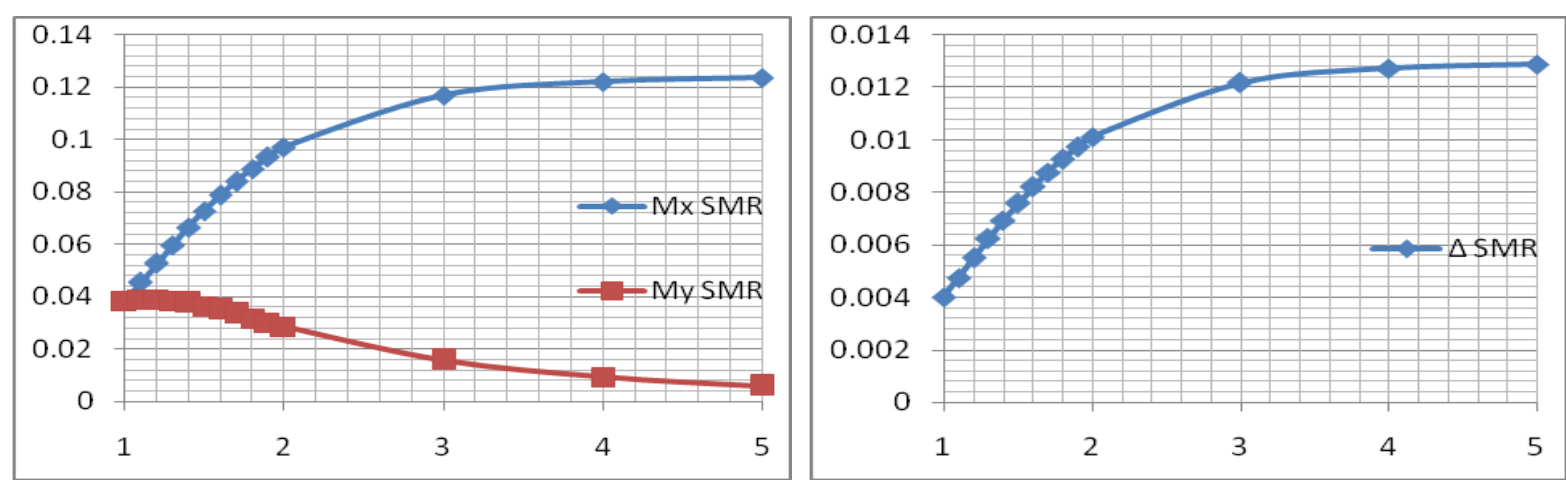

chart 4: load ratio in the $x-x, y-y$ and $x y$ direction together with the bending moments in the $x-x$ and $y-y$ spans of a s-s udl rectangular plate with corners held down. the deflection of the plate is also shown for $\mathrm{h}=0.25$ and $v$ $=0$. graphical representations are also shown. 

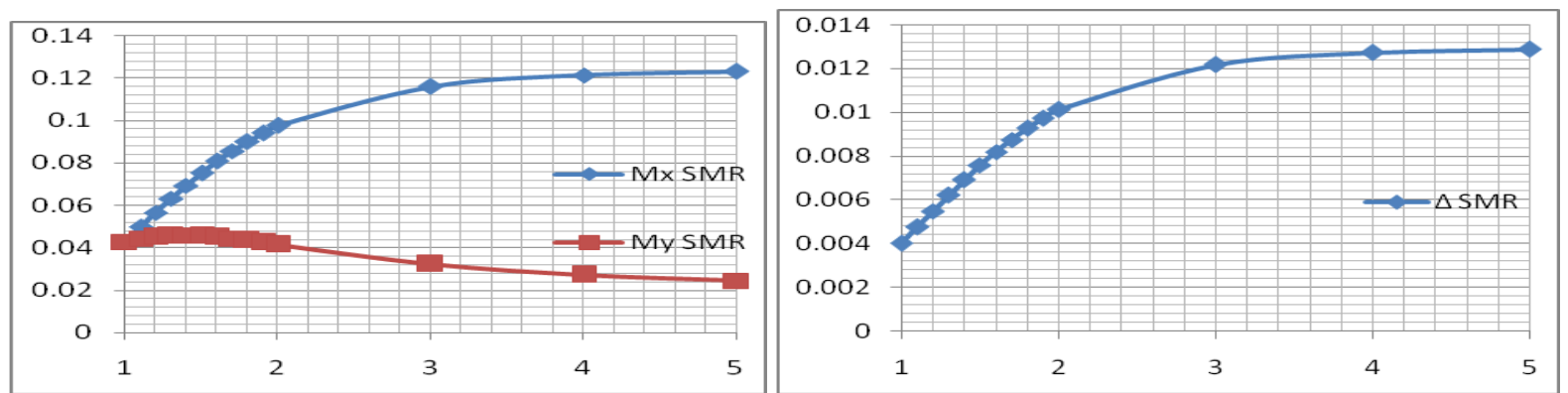

chart 5: load ratio in the $\mathrm{x}-\mathrm{x}, \mathrm{y}-\mathrm{y}$ and $\mathrm{xy}$ direction together with the bending moments in the $\mathrm{x}-\mathrm{x}$ and $\mathrm{y}-\mathrm{y}$ spans of a s-s udl rectangular plate with corners held down. the deflection of the plate is also shown for $\mathrm{h}=0.25$ and $v$ $=0.15$. graphical representations are also shown.
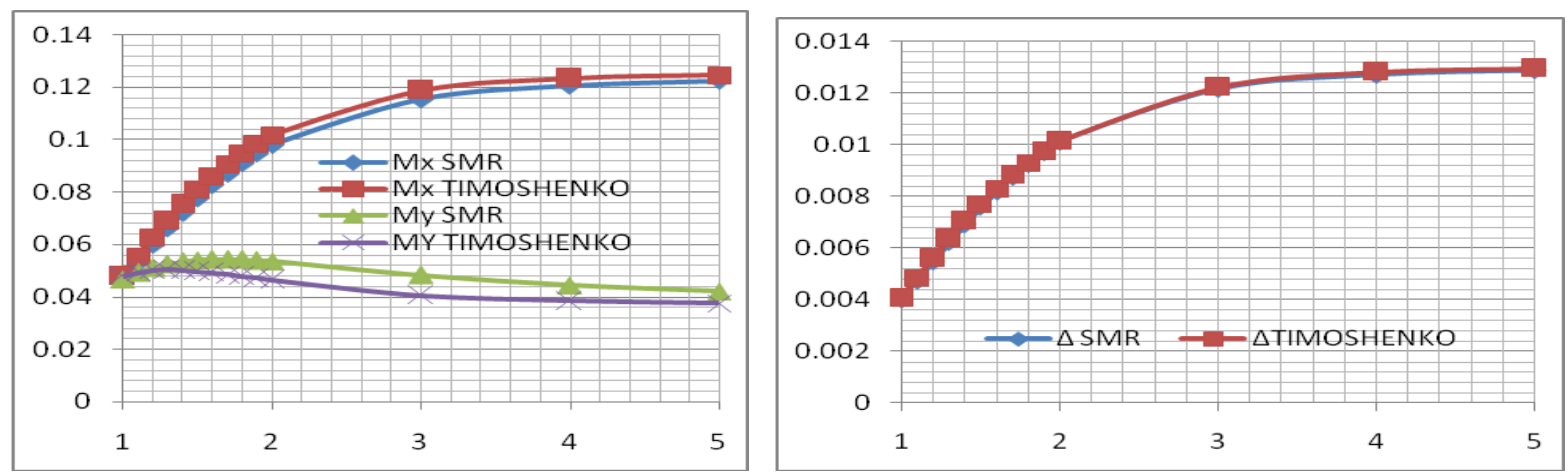

chart 6: load ratio in the $\mathrm{x}-\mathrm{x}, \mathrm{y}-\mathrm{y}$ and $\mathrm{xy}$ direction together with the bending moments in the $\mathrm{x}-\mathrm{x}$ and $\mathrm{y}-\mathrm{y}$ spans of a s-s udl rectangular plate with corners held down. the deflection of the plate is also shown for $\mathrm{h}=0.25$ and $v$ $=0.3$. classical results from timoshenko is also shown. graphical representations are also shown.
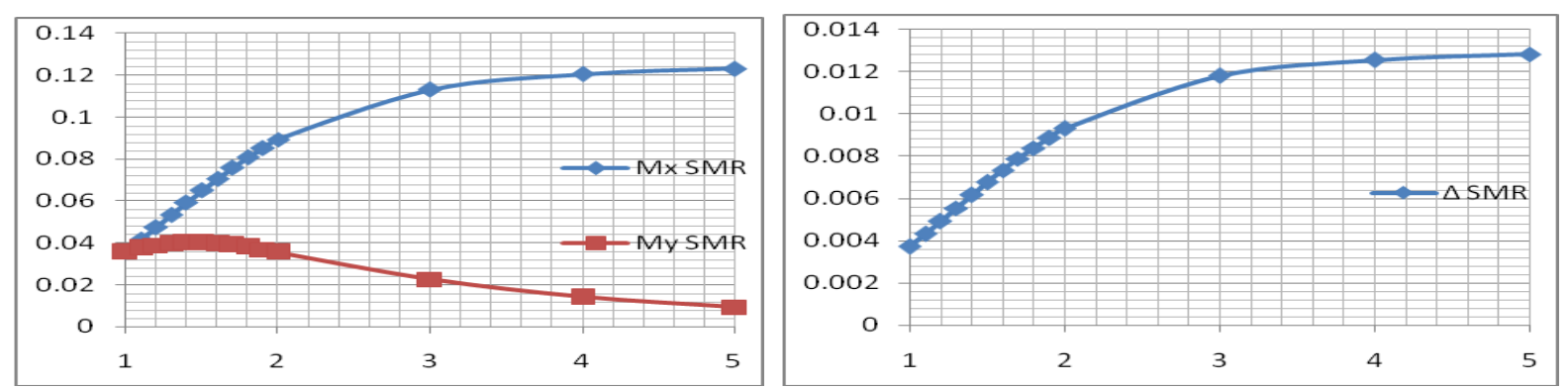

chart 7: load ratio in the $\mathrm{x}-\mathrm{x}, \mathrm{y}-\mathrm{y}$ and $\mathrm{xy}$ direction together with the bending moments in the $\mathrm{x}-\mathrm{x}$ and $\mathrm{y}-\mathrm{y}$ spans of a s-s udl rectangular plate with corners held down. the deflection of the plate is also shown for $\mathrm{h}=0.5$ and $V$ $=0$. graphical representations are also shown.
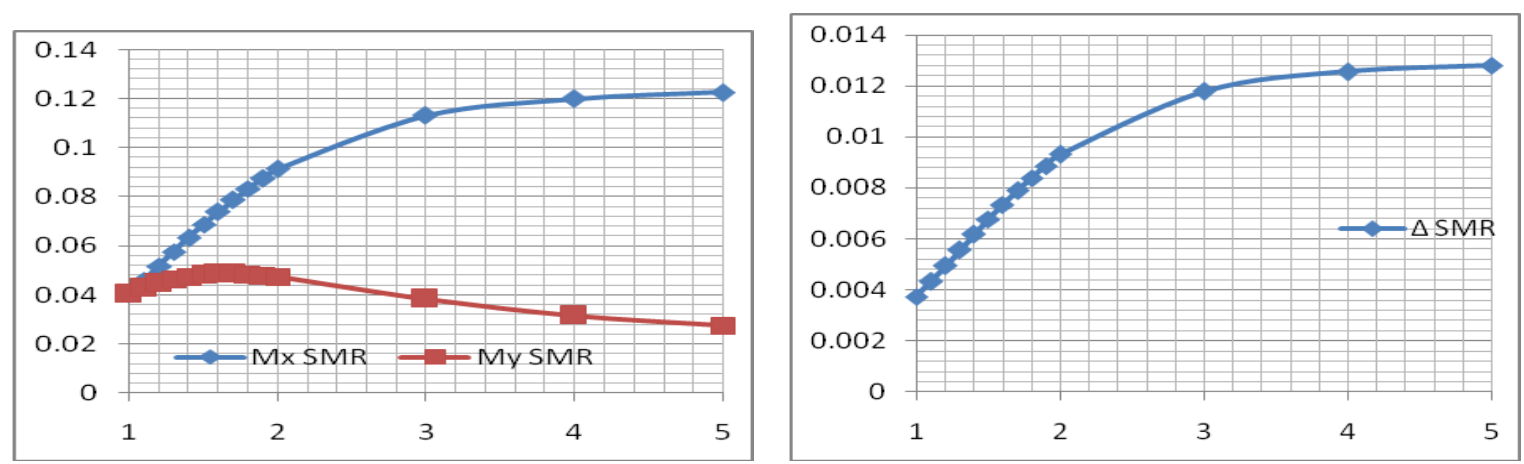

chart 8: load ratio in the $\mathrm{x}-\mathrm{x}, \mathrm{y}-\mathrm{y}$ and $\mathrm{xy}$ direction together with the bending moments in the $\mathrm{x}-\mathrm{x}$ and $\mathrm{y}-\mathrm{y}$ spans of a s-s udl rectangular plate with corners held down. the deflection of the plate is also shown for $\mathrm{h}=0.5$ and $v$ $=0.15$. graphical representations are also shown . 

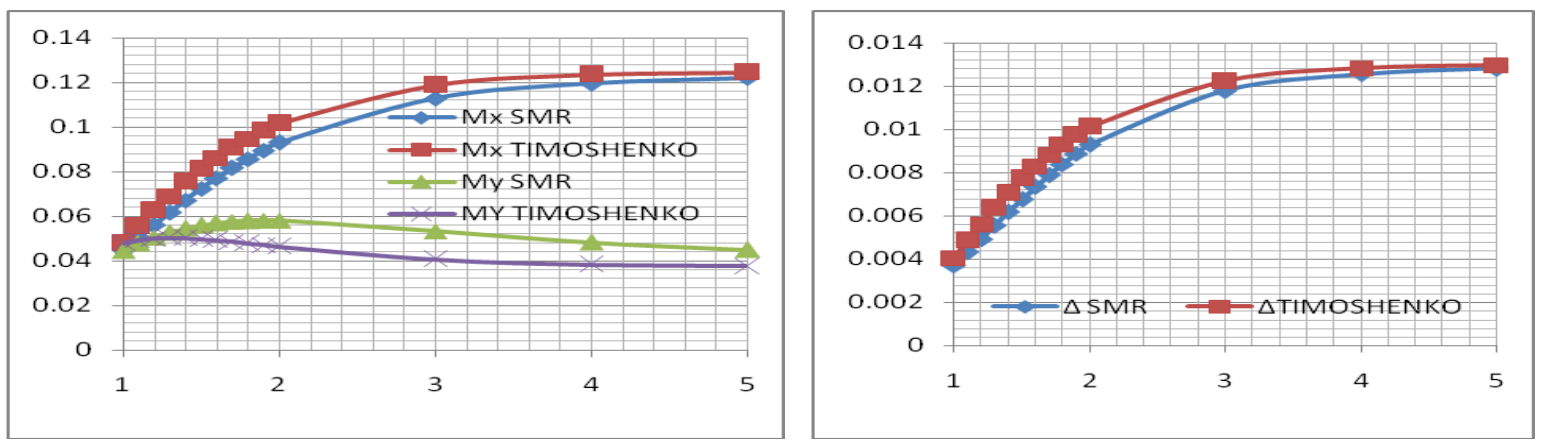

chart 9: load ratio in the $x-x, y-y$ and $x y$ direction together with the bending moments in the $x-x$ and $y-y$ spans of a s-s udl rectangular plate with corners held down. the deflection of the plate is also shown for $\mathrm{h}=0.5$ and $V$ $=0.3$. classical results from timoshenko is also shown. graphical representations are also shown.
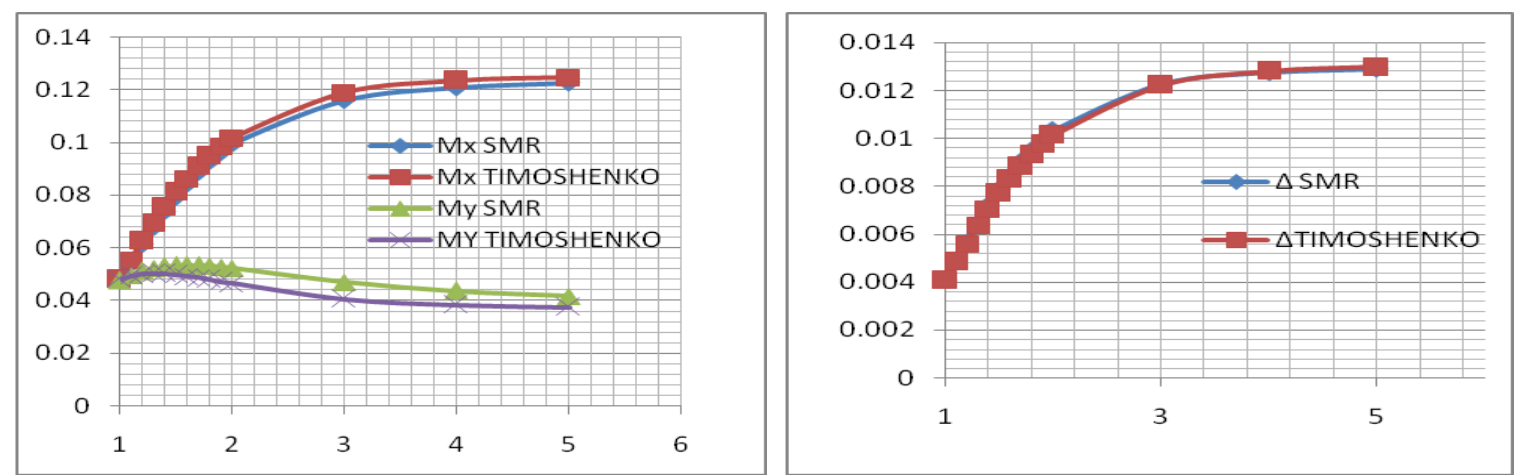

chart 10: load ratio in the $\mathrm{x}-\mathrm{x}, \mathrm{y}-\mathrm{y}$ and $\mathrm{xy}$ direction together with the bending moments in the $\mathrm{x}-\mathrm{x}$ and $\mathrm{y}-\mathrm{y}$ spans of a s-s udl rectangular plate with corners held down. the deflection of the plate is also shown for $\mathrm{h}=0.15$ and $v$ $=0.3$. classical results from timoshenko is also shown. graphical representations are also shown.

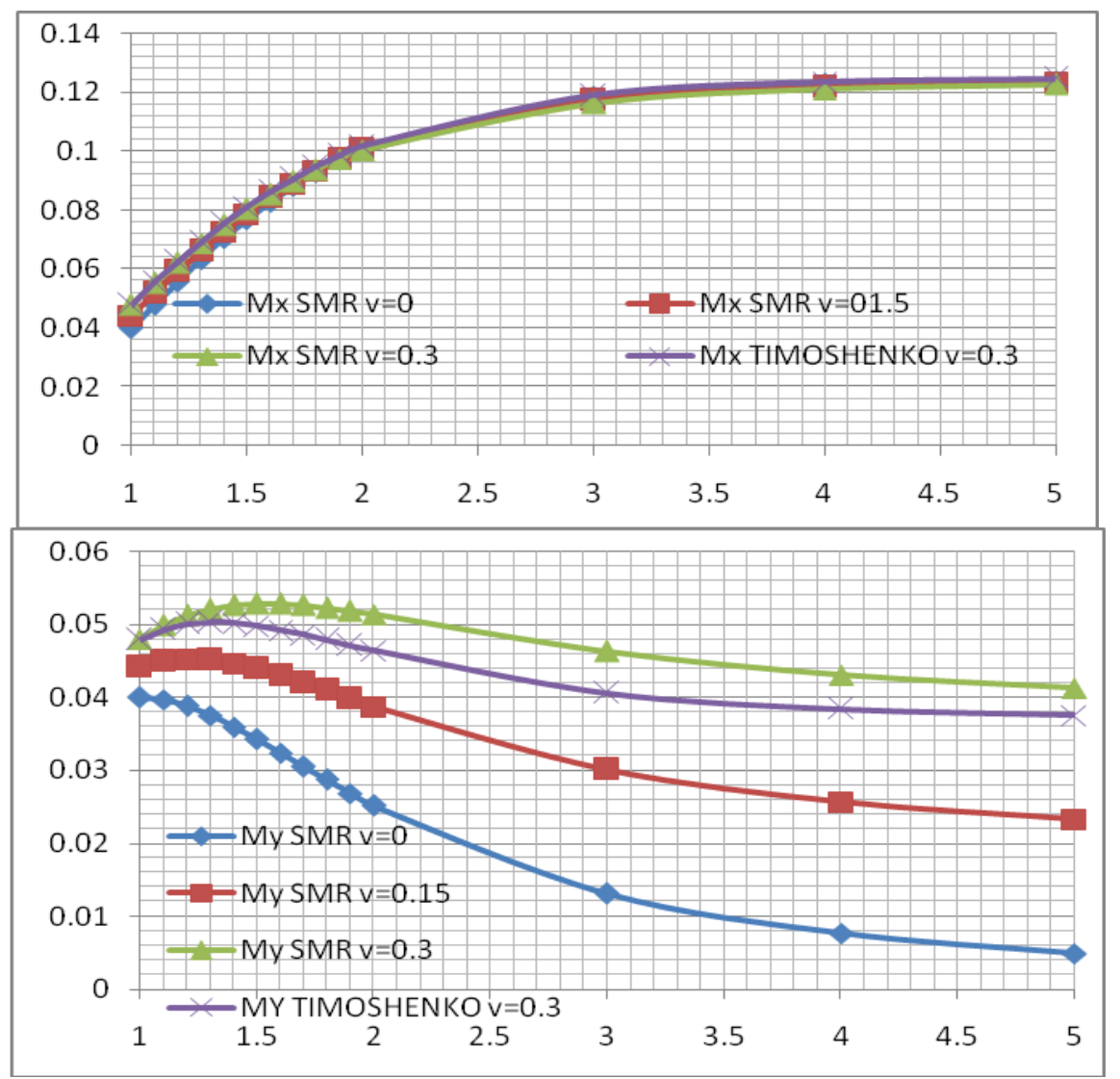




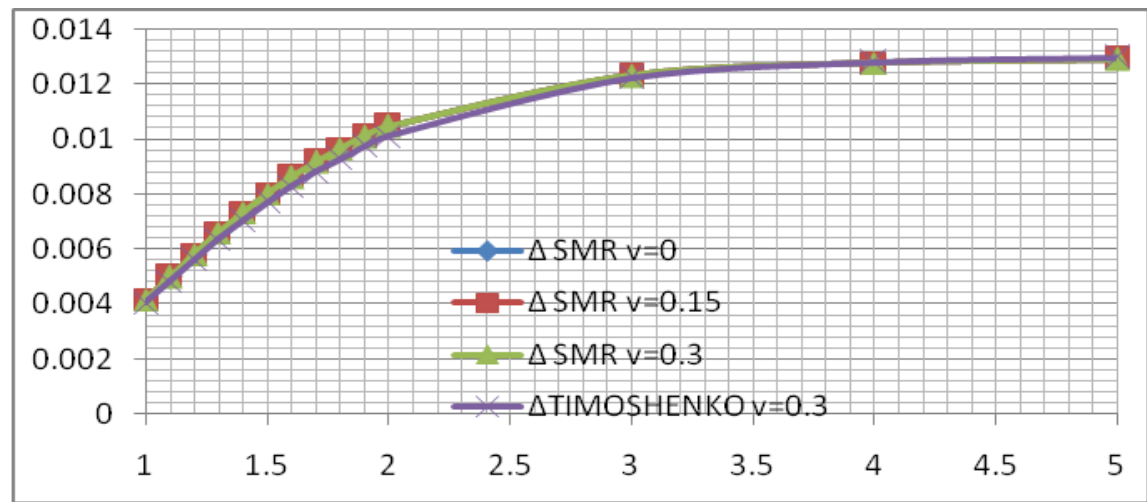

chart 11: showing the effect of various poisson ratios on deflection and bending moments of a s-s udl rectangular plate with corners held down. this is for different aspect ratio and for $\mathrm{h}=0$ and $v=0,0.15$ and 0.3 .

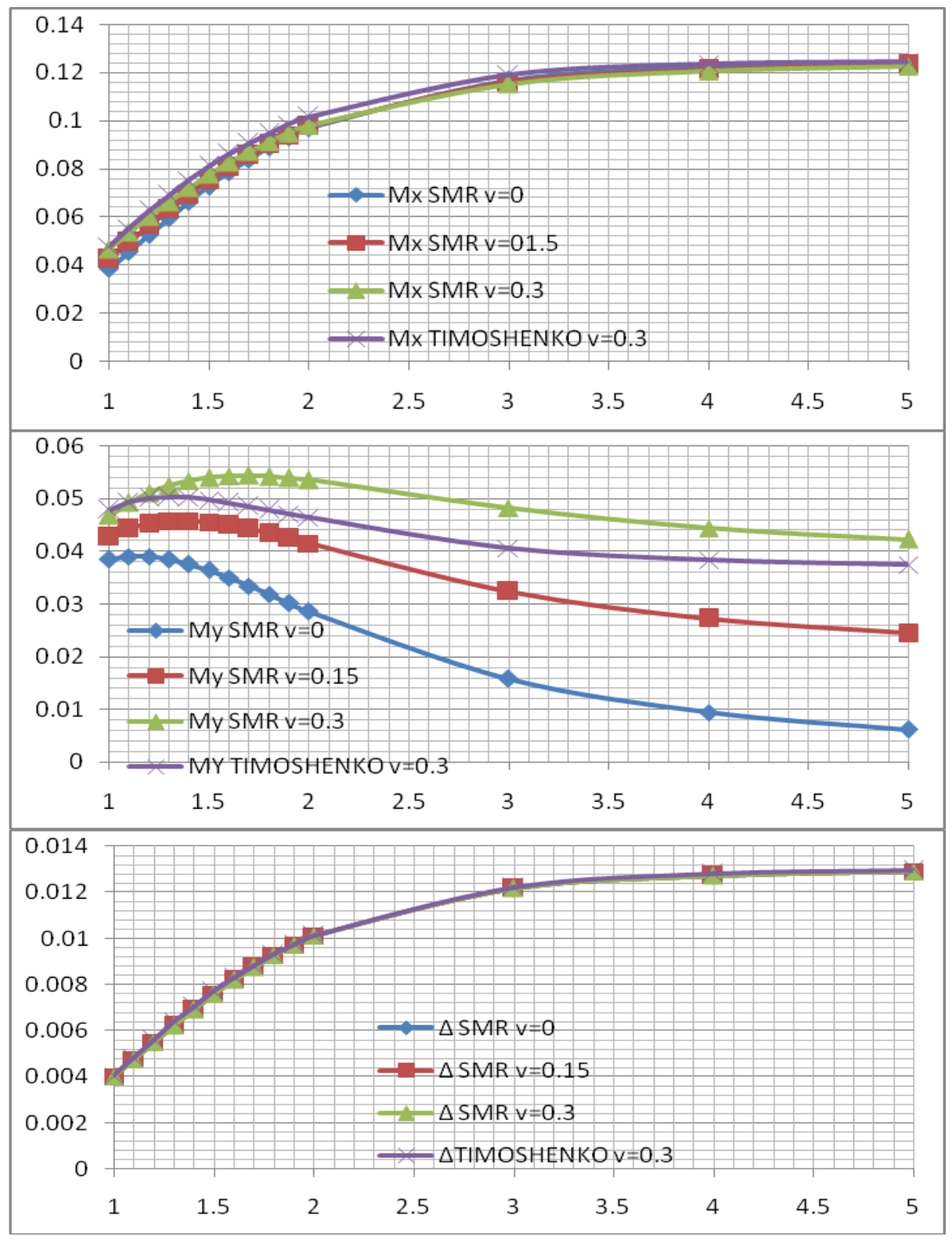

Chart 12: showing the effect of various poisson ratios on deflection and bending moments of a s-s udl rectangular plate with corners held down. This is for different aspect ratio and for $\mathrm{h}=0.25$ and $v=0,0.15$ and 0.3 . 


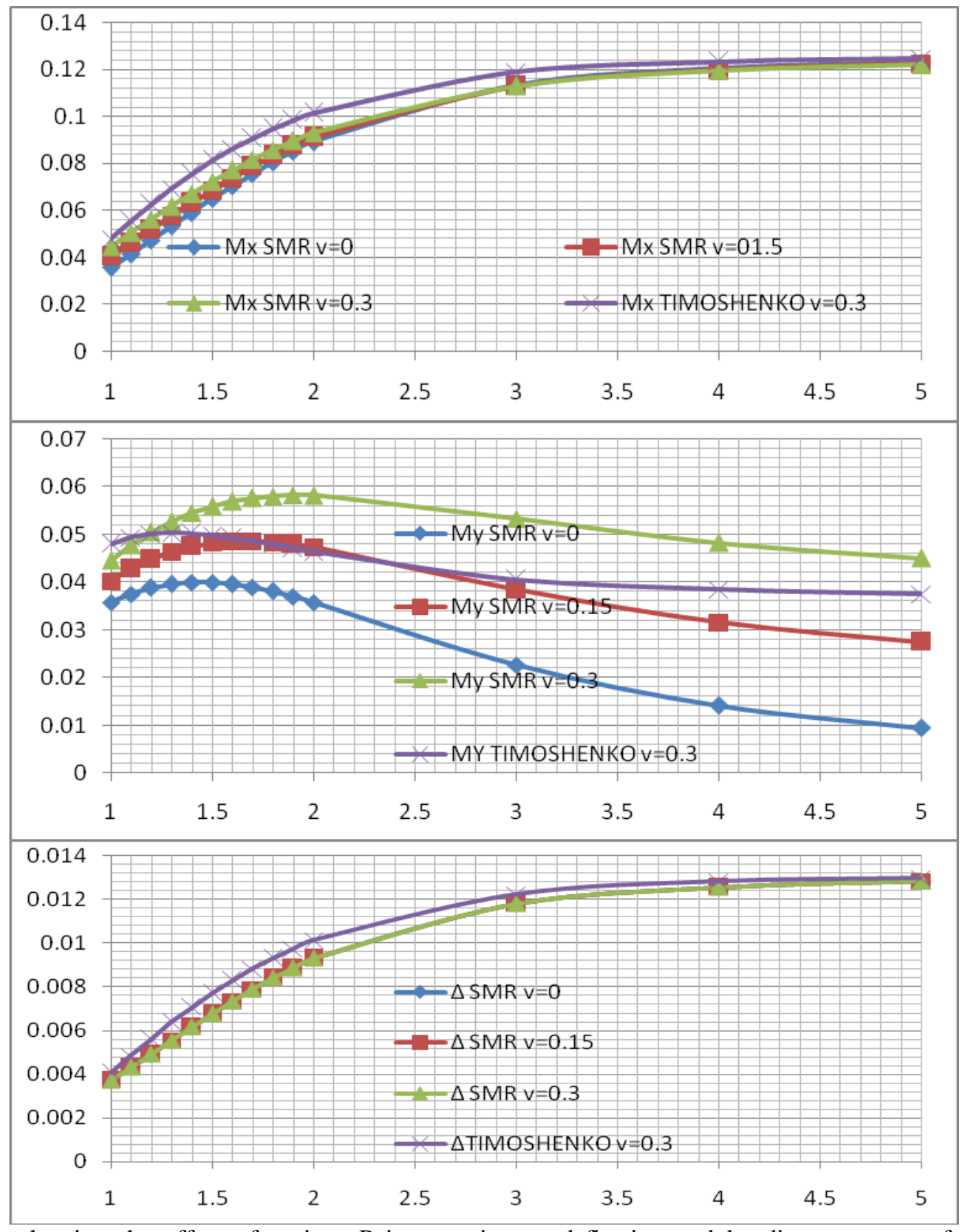

Chart 13: showing the effect of various Poisson ratios on deflection and bending moments of a s-s udl rectangular plate with corners held down. This is for different aspect ratio and for $\mathrm{h}=0.5$ and $v=0,0.15$ and 0.3.

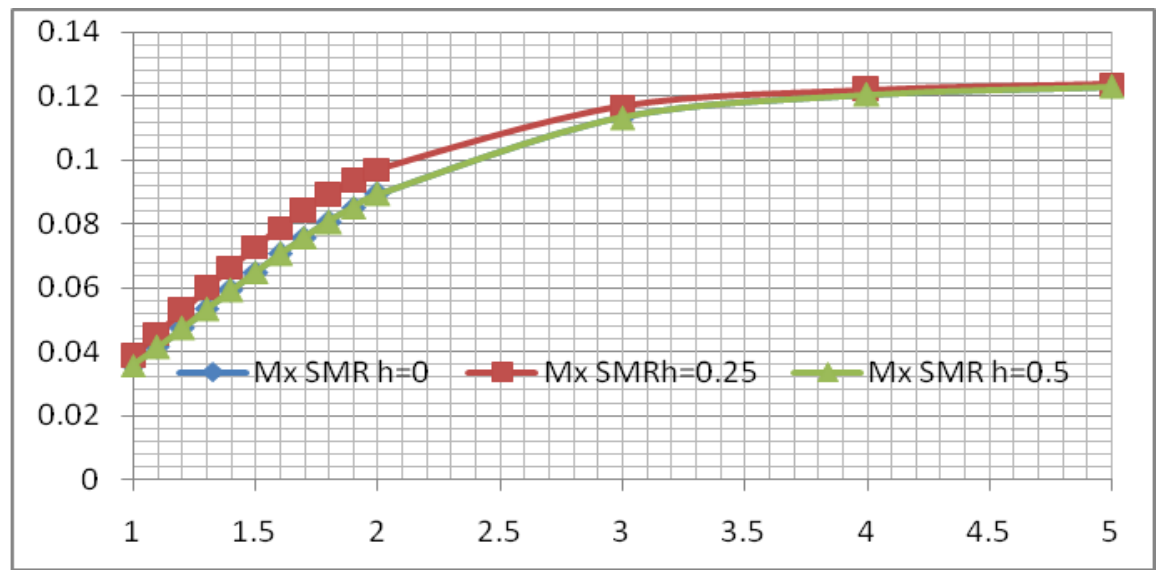




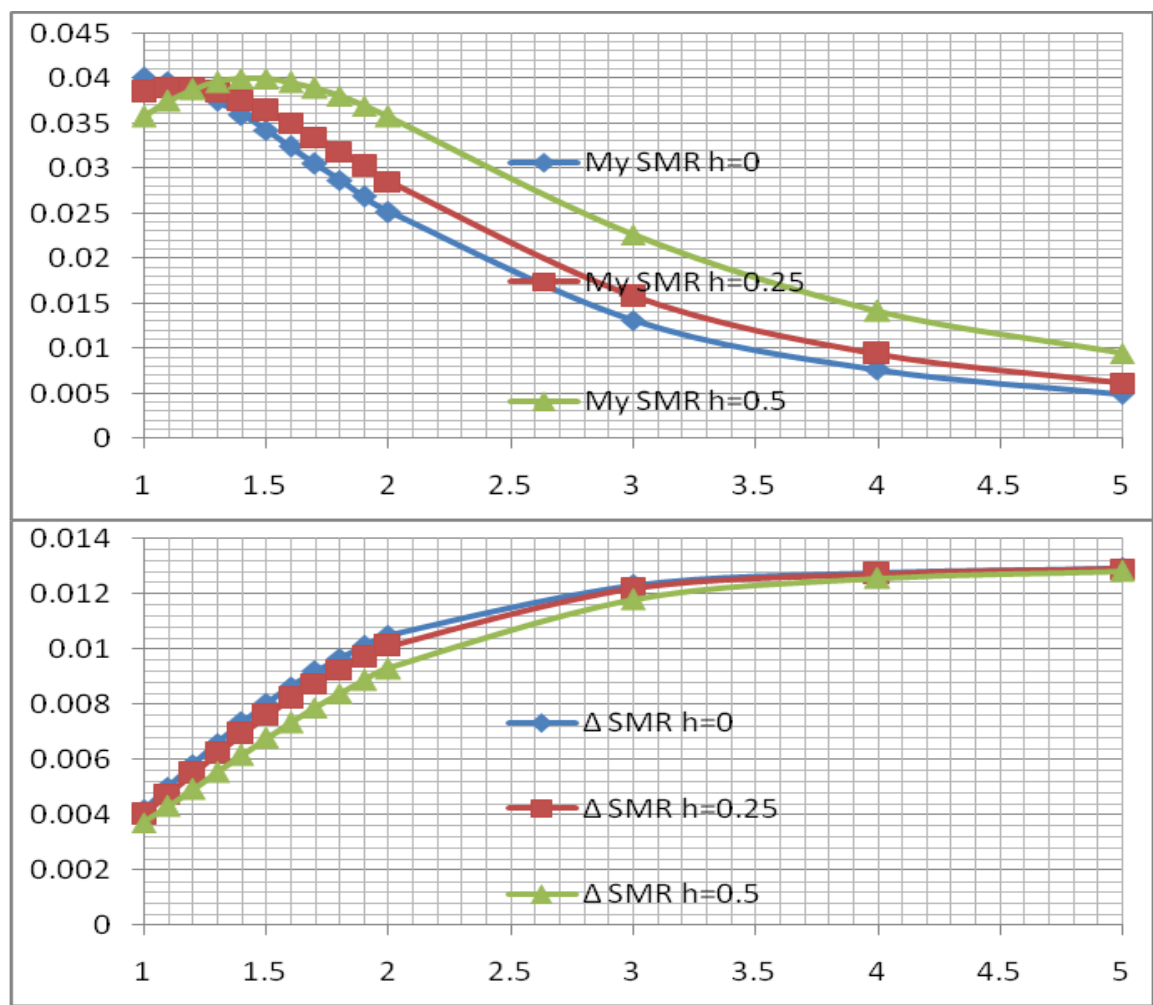

chart 14: showing the effect of various serviceability $\mathrm{h}$ on deflection and bending moments of a s-s udl rectangular plate with corners held down. this is for different aspect ratio and for $v=0$ and $\mathrm{h}=0,0.25$ and 0.5 .

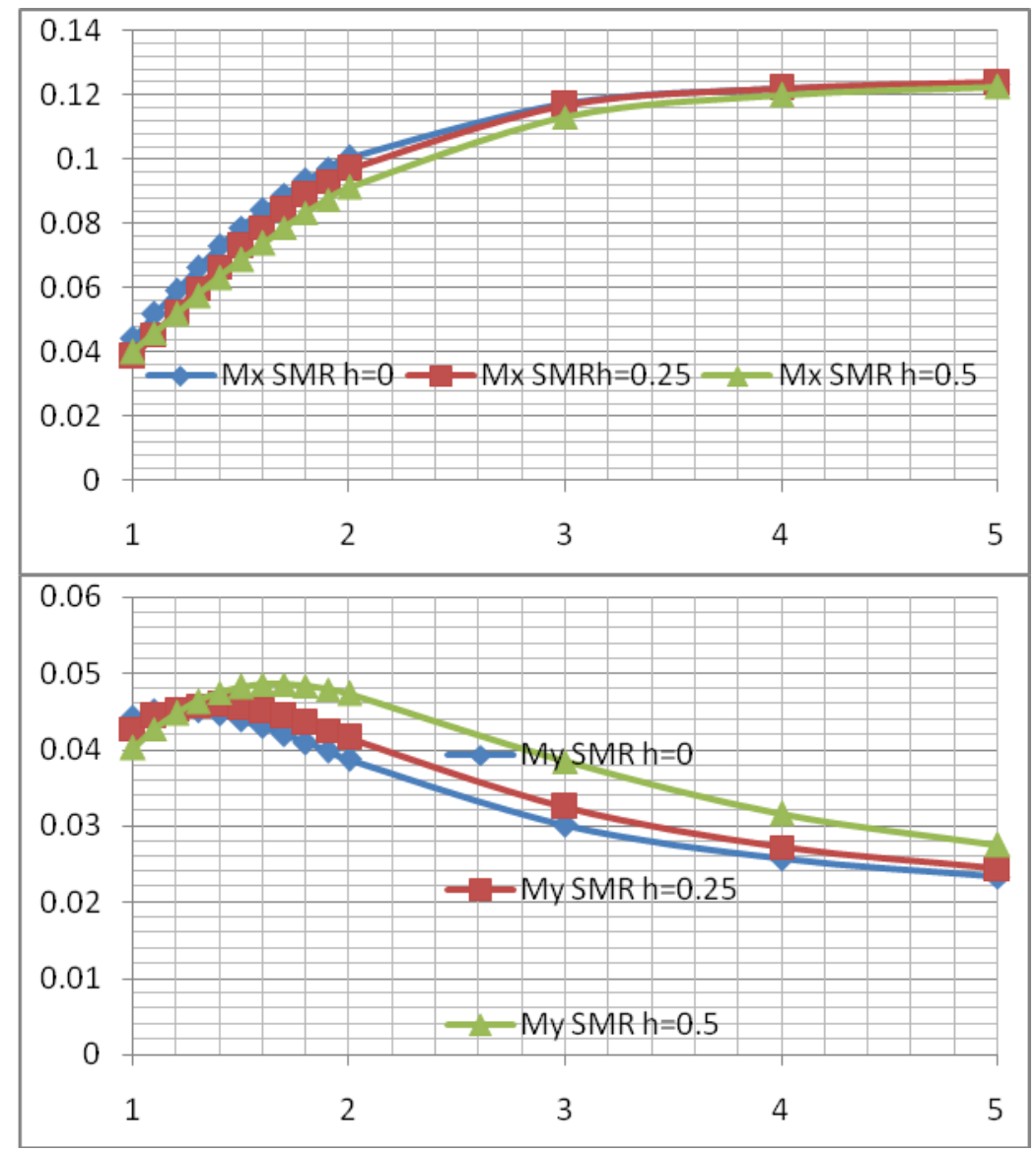




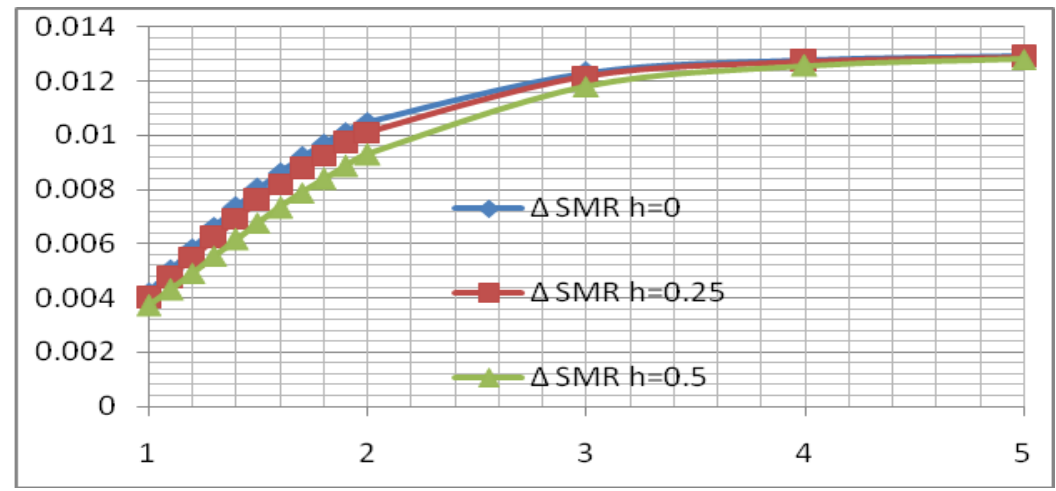

chart 15: showing the effect of various serviceability $\mathrm{h}$ on deflection and bending moments of a s-s udl rectangular plate with corners held down. this is for different aspect ratio and for $v=0.15$ and $\mathrm{h}=0,0.25$ and 0.5 .

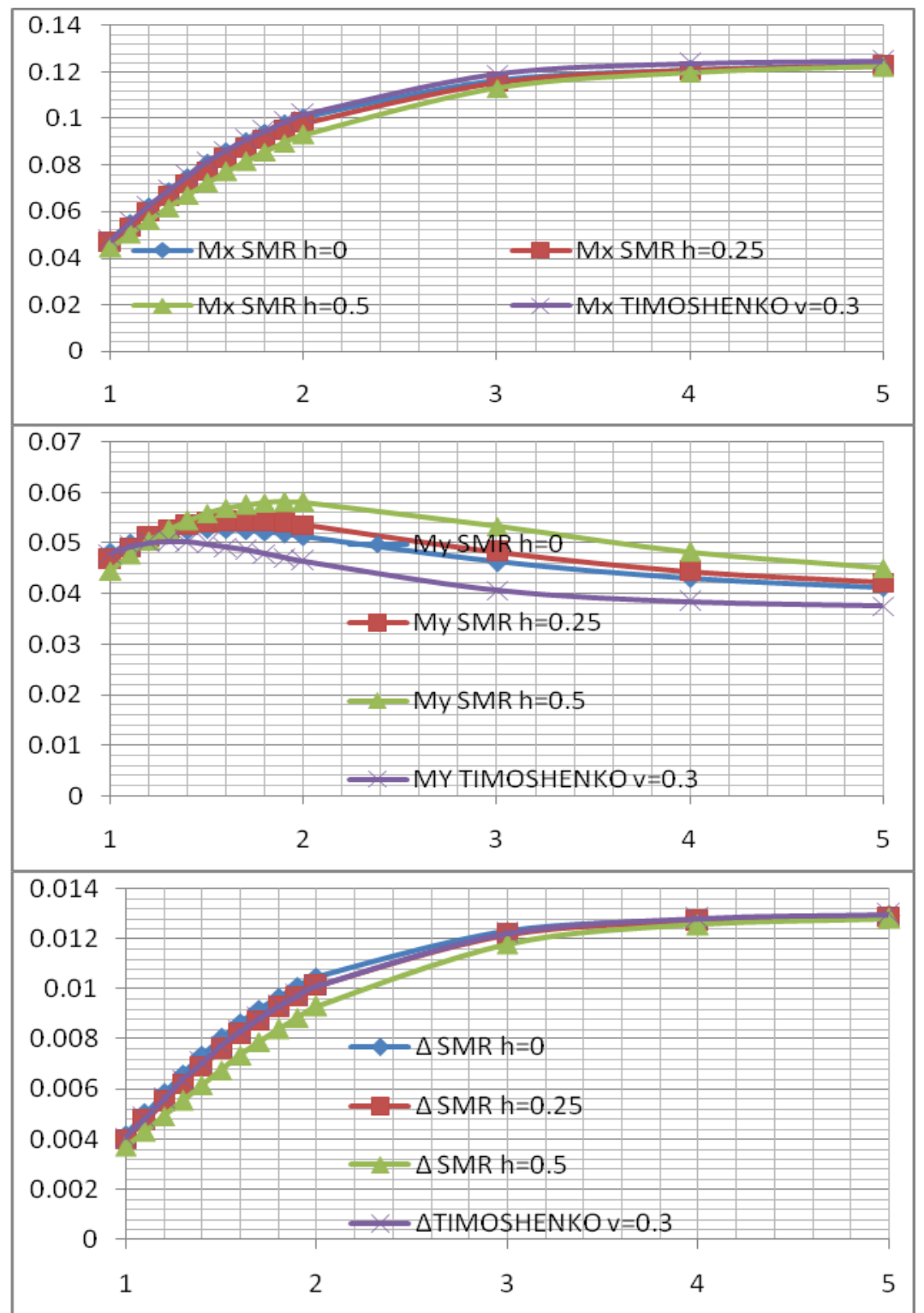

chart 16: showing the effect of various serviceability $\mathrm{h}$ on deflection and bending moments of a s-s udl rectangular plate with corners held down. this is for different aspect ratio and for $v=0.3$ and $\mathrm{h}=0,0.25$ and 0.5 . 